\title{
PRINCIPIA IURIS: UNA TEORÍA DEL DERECHO NO (NEO)CONSTITUCIONALISTA PARA EL ESTADO CONSTITUCIONAL *
}

\author{
Luis Prieto Sanchís** \\ Universidad de Castilla-La Mancha
}

RESUMEN. La teoría del Derecho de Principia iuris asume el nuevo paradigma del Estado constitucional de Derecho y está especialmente diseñada para dar minuciosa cuenta del mismo. Sin embargo, se distancia de las construcciones más usuales del neoconstitucionalismo en dos aspectos capitales, que aquí son objeto de análisis. En el aspecto metodológico o conceptual, se mantiene firmemente la perspectiva ilustrada y positivista de la separación conceptual entre Derecho y moral, frente a las actuales revisiones "postpositivistas» o «neoiusnaturalistas». En el aspecto teórico, y a diferencia también del neoconstitucionalismo, se mantiene una posición más escéptica o menos confiada en las posibilidades de la argumentación jurídica, lo que tiene dos consecuencias principales: una visión más restrictiva de la aplicación directa de la Constitución y una visión no conflictualista de los derechos fundamentales en la línea de la llamada teoría interna.

Palabras clave: FerRajoli, Principia iuris, neoconstitucionalismo, separación conceptual entre Derecho y moral, derechos fundamentales.

ABSTRACT. The Principia luris legal theory adopts the new paradigm of constitutional State of Law and has been specifically designed to account for it. However, it takes exception to the more frequent constructions of neo-constitutionalism for two prime aspects, which will be considered in this text. In the methodological or conceptual sense it firmly maintains the enlightened and positivist stance of the conceptual separation between law and morals against the current postpositivist or neoiusnaturalist approaches. In the theoretical sense, it differs from neo-constitutionalism in that a more sceptical or doubtful approach is adopted with regards to the possibilities of legal argumentation, resulting in two main consequences: a more restricted view of the direct application of the Constitution as well as a non-conflictualist view of the fundamental rights along the lines of the so-called internal theory.

Keywords: Ferrajol, Principia luris, neo-constitutionalism, conceptual separation between law and morals, fundamental rights.

* Fecha de recepción: 1 de diciembre de 2008. Fecha de aceptación: 18 de diciembre de 2008.

** Al hilo de la lectura de Principia Iuris, este trabajo en parte reproduce y en parte matiza y desarrolla ideas ya expuestas en otro precedente, «Constitucionalismo y garantismo», en M. CARBONELL y P. SALAZAR (eds.), 2005: Garantismo. Estudios sobre el pensamiento jurídico de Luigi Ferrajoli, Madrid: Trotta, pp. 41 y ss. 


\section{UNA TEORÍA DEL DERECHO DEL ESTADO CONSTITUCIONAL}

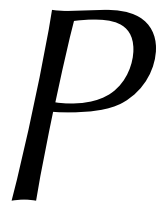

rincipia Iuris no es sólo una teoría del Derecho para el Estado constitucional; sus conceptos más generales y elementales presentan un alcance más amplio, válido para explicar sistemas jurídicos precedentes e incluso sistemas normativos no jurídicos. Sin embargo, los conceptos más elaborados y complejos pretenden dar cuenta y adquieren toda su fuerza explicativa sólo a la luz del modelo constitucionalista. El propio FERRAJOLI lo confiesa desde la primera página de la obra: la finalidad perseguida por la teoría «es la redefinición del paradigma teórico y normativo de las modernas democracias constitucionales»; de ahí que pueda decirse que «la teoría (normativa) de la democracia es el banco de pruebas de la teoría (formal) del Derecho de los modernos ordenamientos constitucionales» ${ }^{1}$.

De manera que Principia Iuris puede considerarse también como la teoría jurídica del garantismo por cuanto, como viene repitiendo el autor, «el paradigma garantista es uno y el mismo que el del actual Estado constitucional de Derecho» ${ }^{2}$, representando «la otra cara del constitucionalismo», concretamente aquella que se encarga de «formular las técnicas de garantía idóneas para asegurar el máximo grado de efectividad de los derechos reconocidos constitucionalmente» ${ }^{3}$. En otras palabras, el Estado constitucional de Derecho viene a expresar la fórmula política del garantismo, el único marco institucional en el que puede prosperar su ambicioso programa cuyo elemento medular consiste en una concepción artificial de las instituciones al servicio de los derechos.

Ciertamente, el Estado constitucional tampoco presenta unos rasgos uniformes u homogéneos en todas sus manifestaciones, ofreciendo versiones más o menos vigorosas de control del poder. Como ha observado GUASTINI, la constitucionalización debe concebirse como un proceso, no como una cualidad todo o nada, que se va fortaleciendo o enriqueciendo con sucesivos elementos o exigencias ${ }^{4}$ : fuerza normativa o vinculante, aplicación directa por los jueces y funcionarios sin necesidad de interposición legislativa, mayor o menor rigidez frente a la reforma, garantía jurisdiccional más o menos amplia o eficaz, etc.; y, sobre todo por lo que aquí interesa, una densidad variable de contenido normativo. En relación con este último aspecto, podríamos dividir las Constituciones en dos grandes categorías ideales: Constituciones formales o procedimentales, cuyo objeto exclusivo sería organizar el poder y, con ello, las fuentes del Derecho (norma normarum), indicando quién manda y cómo manda, pero dejando que sean luego los distintos órganos estatales quienes decidan qué debe mandarse o prohibirse; y las Constituciones materiales o sustantivas, que incorporarían un programa político cerrado que prácticamente asfixiaría la libertad política del legislador y de las

\footnotetext{
${ }^{1}$ Principia Iuris. Teoria del diritto e della democrazia, 3 vols., Bari: Laterza, 2007, Prefacio, pp. V y VII.

${ }^{2}$ L. Ferrajoli, 1999: «Garantías», trad. de A. DE CABO y G. PISARELlo, 2000: Jueces para la democracia, 38 , p. 40.

3 L. FerRAJOLI, 2002: «Juspositivismo crítico y democracia constitucional», trad. de L. CóRDOVA y P. SALAZAR, Isonomia, 16, p. 16. De ahí que en Principia Iuris se hable a veces indistintamente del «paradigma constitucional o garantista»; así en $₫ 12.1$, vol. I, p. 849.

${ }^{4}$ R. GUASTINI, 1998: «La "constitucionalización” del ordenamiento jurídico: el caso italiano», en M. CARBONELL (ed. y presentación), 2001: Estudios de teoría constitucional, México: UNAM, pp. 153 y ss.
} 
demás instituciones, que se convertirían así en meros ejecutores del documento constitucional $^{5}$.

Lógicamente, ninguna de estas categorías se dan en estado puro: las Constituciones, por muy formales que sean, necesariamente han de incorporar algunos preceptos sustantivos, aunque sólo sea para asegurar las condiciones de la formación democrática de la ley; y, por muy material que quiera ser, ninguna Constitución podría descender a la regulación de tantos detalles que hiciera superflua la acción del legislador. Pero, aunque no puedan encontrarse en estado puro, todas las Constituciones se aproximan a uno u otro modelo e incluso podríamos designarlas con un nombre: Constituciones Kelsen y Constituciones Ferrajoli. KeLSEN, en efecto, tal vez sea el autor que, tomándose en serio la fuerza normativa de la Constitución, más dificultades y cautelas mostró a la hora de incorporar al texto principios o derechos, en suma, límites materiales a la acción del legislador ${ }^{6}$. FERRAJOLI, por su parte, quizás sea el autor que, tomándose en serio la democracia parlamentaria, ha construido un modelo más denso y vigoroso de Constitución normativa. Este es el núcleo del paradigma del constitucionalismo moderno: la regulación no sólo del quién y del cómo se manda, sino también de qué puede o debe mandarse; no sólo normas de competencia y procedimiento, condicionantes de la vigencia de la ley, sino también normas sustantivas condicionantes de su validez. Si la regulación de las formas caracteriza al positivismo jurídico y al Estado de Derecho en sentido débil, «la regulación de sus significados mediante normas sustantivas caracteriza en cambio al constitucionalismo y al Estado de derecho en sentido fuerte, que exigen que todos los poderes, incluso el legislativo, se hallen sometidos a límites y vínculos de contenido»?

En la fórmula garantista, en efecto, el respeto por las reglas de la democracia, esto es, por las formas y procedimientos de producción democrática de las leyes, es una condición necesaria y suficiente para asegurar la vigencia o validez formal, pero no así la validez sustancial de las decisiones: «para que una ley sea válida es además necesaria la coherencia de sus significados con las reglas y principios que bien podemos llamar normas sustantivas sobre la producción [...] Estas reglas son esencialmente las establecidas generalmente en la primera parte de las cartas constitucionales» ${ }^{8}$.

La versión del constitucionalismo que se desprende de Principia Iuris resulta particularmente vigorosa ${ }^{9} \mathrm{y}$ bien pudiera llamarse constitucionalismo rematerializado o de los derechos. Justamente, lo que caracteriza a las modernas democracias constituciona-

5 Es bastante citada la imagen de E. FORSTHOFF cuando critica a quienes quieren ver en la Constitución una especie de huevo jurídico del que todo surge, desde el Código Penal a la Ley sobre fabricación de termómetros, El Estado en la sociedad industrial, 1971, trad. de L. LÓPEZ GuERRA y J. NiCOLÁs MuÑIZ, 1975: Madrid: Instituto de Estudios Políticos, p. 242.

6 Y ello expresamente ante el temor de que los jueces se convirtiesen en los auténticos señores de la Constitución. De KELSEN vid., por ejemplo, 1928: «La garantía jurisdiccional de la Constitución (la justicia constitucional)», en J. RUIZ MANERO (ed.), 1988: Escritos sobre la democracia y el socialismo, Madrid: Debate, pp. 142 y ss.

7 Principia Iuris, $\$ 9.17$, vol. I, p. 567.

8 L. FerRajoli, 2003: «Sobre la definición de "democracia”. Un discusión con M. Bovero», trad. de N. GuZMán, Isonomía, 19, p. 230.

9 Como «constitucionalismo fortísimo» ha sido calificado por P. DE LORA, «Luigi Ferrajoli y el constitucionalismo fortisimo», en Garantismo. Estudios sobre el pensamiento jurídico de Luigi Ferrajoli, cit., pp. 251 y ss. 
les es el sometimiento del Derecho al Derecho «no sólo en cuanto a la forma de producción, sino también en cuanto a los contenidos producidos»; son las normas sustantivas, en particular los derechos fundamentales, las que están en la base «del constitucionalismo jurídico, es decir, de la positivación no sólo del "ser" sino también del "deber ser" del Derecho manifestada en el que he llamado principio de estricta legalidad» ${ }^{10}$. Por eso, en el marco del Estado constitucional de Derecho «no existen poderes soberanos o legibus soluti ${ }^{11}$, pues el ejercicio de todos ellos viene sometido a requisitos formales acerca del quién y del cómo se manda y, sobre todo, a requisitos materiales o sustantivos acerca de qué puede o debe mandarse.

Se forman así tres esferas a propósito de las decisiones políticas: la esfera de lo indecidible, constituida «por el conjunto de los derechos de libertad y de autonomía que impiden, en cuanto expectativas negativas, decisiones que puedan lesionarlos o reducirlos; la esfera de lo indecidible que no, determinada por el conjunto de los derechos sociales que imponen, en cuanto expectativas positivas, decisiones dirigidas a satisfacerlos»; y la esfera de lo decidible, «en cuyo interior es legítimo el ejercicio de los derechos de autonomía» ${ }^{12}$, tanto de la autonomía política mediante la representación, como de la autonomía privada según las reglas del mercado ${ }^{13}$. En la democracia constitucional forma y sustancia se asocian a las distintas tipologías de derechos fundamentales: la democracia formal aparece generada por los derechos de autonomía que determinan quién y cómo se manda; la democracia sustancial viene delimitada por los derechos de libertad que dan lugar a obligaciones de abstención o respeto de ámbitos de inmunidad (lo indecidible) y por los derechos sociales que reclaman acciones positivas de dar o de hacer (lo indecidible que no).

Es interesante destacar que en este constitucionalismo sustancial queda cancelada la tradicional tensión entre democracia y Constitución, entre decisión mayoritaria y derechos, que tanto preocupa a la concepción que el propio FERRAJOLI llama politicista o mayoritarista. No hay espacio para la conocida objeción contramayoritaria porque no se conciben dos fuentes de legitimidad en permanente conflicto: los límites y vínculos que pesan sobre el legislador son «a su vez democráticos, ya que consisten en derechos fundamentales, que son derechos de todos, y hacen referencia por tanto al pueblo — como conjunto de personas de carne y hueso que lo componen- en un sentido más directo y consistente de cuanto lo hace la propia representación política. Son contra-poderes, fragmentos de soberanía popular en manos de todos y cada uno» ${ }^{14}$. La democracia es al mismo tiempo formal y sustancial, desmintiendo la divulgada concepción «de la liberal-democracia como sistema fundado sobre una serie de reglas que aseguran la omnipotencia política de la mayoría y la absoluta libertad de la economía de mercado», pues precisamente la garantía tanto de la autonomía política como de la negocial reside, «con apa-

${ }_{10}$ Principia Iuris, cit. $\$ 12.1$, vol. I, p. 848.

11 Ibídem, $\mathbb{\$} 12.2$, vol. I, p. 854.

12 L. FERRAJOLI, «Sobre la definición de “democracia”», cit., p. 231.

13 Vid. una caracterización más precisa en L. FERRAJOLI, 1989: Derecho y razón. Teoría del garantismo penal, trad. de P. Andrés, A. Ruiz Miguel, J. C. BAyón, J. Terradillos y R. Cantarero, Madrid: Trotta, 1995 , pp. 855 y ss.; Los fundamentos de los derechos fundamentales, A. DE CABO y G. PISARELlo (eds.), Madrid: Trotta, 2001, pp. 35, 167 y 339 y ss.; Principia Iuris, cit., $\$ 11.18$, vol. I, pp. 814 y ss.

14 L. FERRAJOLI, 2006: Garantismo. Una discusión sobre derecho y democracia, trad. de A. GREPPI, Madrid: Trotta, pp. 99 y ss. 
rente paradoja», en su inderogabilidad política y en su indisponibilidad privada; es decir, en representar, junto con los demás derechos fundamentales, un límite infranqueable frente a los poderes mayoritarios y del mercado ${ }^{15}$. En resumen, el paradigma del Estado constitucional, heredero de la filosofía contractualista, supone que el consenso de los contratantes «no es un acuerdo vacío, sino que tiene como cláusula y como "razón social" la garantía de los derechos fundamentales, cuya violación por parte del soberano legitima la ruptura del pacto, hasta la insurrección y la guerra civil» ${ }^{16}$.

Ahora bien, que el constitucionalismo vertebre toda la teoría jurídica de Principia Iuris no significa que pueda calificarse de neoconstitucionalista. Desde luego, tampoco resulta del todo claro en qué consiste el neoconstitucionalismo, ni cuáles sean sus tesis indubitadas ${ }^{17}$, pero, sin detenerme en la cuestión, sugiero las tres siguientes notas distintivas. Primera, una tesis que pudiéramos llamar metodológica o conceptual dirigida al corazón mismo del positivismo y que viene a sostener la relación necesaria entre Derecho y moral y la primacía del llamado punto de vista interno, si no en todo sistema jurídico (que a veces esto también), sí al menos en los sistemas constitucionales. Segunda, una concepción muy vigorosa de la fuerza normativa de la Constitución que hace de ésta una norma directa e inmediatamente aplicable por los jueces, sin necesidad de interpositio legislatoris. Y tercera, una visión conflictualista de las normas sustantivas de la Constitución y en especial de los derechos fundamentales, que son concebidos al modo de los «principios» (y no de la «reglas») y que reclaman el desarrollo de una depurada argumentación jurídica. Si la primera característica conduce a lo que el propio FERRAJOLI califica de «constitucionalismo ético», la segunda y la tercera están en la base del activismo judicial, un reproche habitualmente formulado al neoconstitucionalismo, pero al que en mi opinión no se hace acreedor FERRAJOLI ${ }^{18}$.

\section{LA PRIMACÍA DEL PUNTO DE VISTA EXTERNO Y LA SEPARACIÓN ENTRE DERECHO Y MORAL}

Como se ha dicho, tal vez el rasgo más destacado del constitucionalismo contemporáneo, y también el principal argumento de las concepciones neoconstitucionalistas,

${ }^{15}$ De ahí que las funciones judiciales de garantía, aunque antimayoritarias, resulten sin embargo democráticas: «en el sentido de que, siendo garantía para todos, tales funciones se refieren al pueblo entero, no ya como representación de su mayoría, sino como conjunto de todas las personas que lo componen», Principia Iuris, cit., $\$ 12.7$, vol. I, p. 877 .

${ }^{16}$ Principia Iuris, cit, $\$ 11.18$, vol. I, p. 823.

${ }_{17}$ Este es un término de reciente incorporación al léxico académico que tanto puede referirse al tipo de Constituciones que han prosperado en la Europa de posguerra, como a ciertas doctrinas o concepciones sobre el Derecho; aunque en este último caso las tesis que se califican como neoconstitucionalistas no son en modo alguno uniformes e incluso a veces resultan opuestas. Véanse S. Pozzolo, 2001: Neocostituzionalismo e positivismo giuridico, Torino: Giappichelli; P. COMANDUCCI, 2002: «Forme di (neo)costituzionalismo: una ricognizione metateorica», en T. MAZZARESE (ed.), Neocostituzionalismo e tutela (sovra)nazionale dei diritti fondamentali, Torino: Giappichelli, pp. 71 y ss.; y en este mismo volumen, T. MAZZARESE, «Diritti fondamentali e neocostituzionalismo: un inventario di problemi», pp. 7 y ss.

${ }^{18}$ M. ATIENZA incluye a FERRAJOLI dentro del paradigma constitucionalista, junto a MACCORMICK, RAZ, AleXY y NINO, 2001: El sentido del Derecho, Barcelona: Ariel, p. 309. En un sentido amplio de constitucionalismo tiene razón, pero creo que FERRAJOLI se distancia bastante en varias de las tesis centrales que el propio ATIENZA atribuye al constitucionalismo, como veremos seguidamente. 
sea la rematerialización, esto es, la (re)incorporación de contenidos sustantivos de carácter moral y político que pretenden condicionar de forma más o menos severa qué es lo que pueden o deben mandar las instituciones y especialmente el poder legislativo. Este fenómeno de la rematerialización constitucional ha sido expresado de muchas formas: la moral «ya no flota sobre el derecho [...] (sino que) emigra al interior del Derecho positivo» ${ }^{19}$, de manera que «el conflicto entre derecho y moral se desplaza al ámbito del Derecho positivo» ${ }^{20}$; cabe decir entonces algo metafóricamente que «el Derecho por principios encuentra al derechos natural» ${ }^{21}$ o que se ha producido una «fusión entre el Derecho constitucional y la teoría ética» ${ }^{22}$ desde el momento en que «la moralidad pública (valores morales) se realiza eficazmente a través del Derecho» ${ }^{23}$. El propio FERRAJOLI ha reconocido un acercamiento entre «legitimación interna o deber ser jurídico y legitimación externa o deber ser extrajurídico» ${ }^{24}$. Dicho de un modo más o menos literario, la conclusión parece unánime: merced a las Constituciones, la moral —es decir, los venerables derechos naturales - han hecho acto de presencia en el Derecho, más concretamente en la cúspide del Derecho.

Esta última matización es interesante porque, en realidad, la moral (la moral social, buena o mala) siempre ha estado presente en el Derecho; las normas jurídicas que no fueran de las llamadas meramente penales siempre han incorporado pautas o estándares de comportamiento de naturaleza moral o sustantiva que le decían al destinatario lo que podía, debía o no debía de hacer. La diferencia, que sin duda tiene suma importancia, es que por lo general dichas normas se dirigían a los ciudadanos y servían para valorar su conducta, mientras que ahora pretenden vincular también a los poderes públicos, cuya conducta se expresa a su vez en forma de normas jurídicas. La consecuencia es entonces que el juicio sobre la validez de las normas se ha convertido en un juicio sustantivo que toma como parámetros normas constitucionales que encarnan al propio tiempo normas de moralidad; singularmente, que expresan derechos fundamentales que son, según opinión común, el compendio de la moral pública de la modernidad. El garantismo necesita del constitucionalismo para hacer realidad su programa ilustrado; y el constitucionalismo se alimenta del proyecto garantista para condicionar la legitimidad del poder al cumplimiento de ciertas exigencias morales que se condensan en los derechos fundamentales.

De aquí se deduce una conclusión que pocos podrán negar, y es que uno de los criterios clásicos de distinción entre Derecho y moral se desvanece. Me refiero a la distinción entre sistemas estáticos y dinámicos: en los primeros una norma es válida o pertenece al sistema cuando su contenido constituye una deducción de otra norma del sistema, del mismo modo que lo particular puede ser subsumido en lo general o universal; en

19 J. HABERMAS, 1981: «¿Cómo es posible la legitimidad por vía de legalidad?», trad. e introducción de M. JIMÉNEZ REDONDO, Escritos sobre moralidad y eticidad, Barcelona: Paidós, p. 168.

${ }^{20}$ R. DREIER, 1985: «Derecho y moral», en E. GARZÓn VALDÉS (comp.), Derecho y filosofía, Barcelona: Alfa, p. 74.

${ }_{21}$ G. Zagrebelsky, 1992: El derecho dúctil, trad. de M. Gascón, epílogo de G. Peces-Barba, Madrid: Trotta, 1985, p. 116.

${ }_{22}^{2}$ R. DwORKIN, 1977: Los derechos en serio, trad. de M. GuASTAvinO, presentación de A. CALSAMiglia, Barcelona: Ariel, 1984, p. 233.

${ }^{23}$ G. PeCES-BARBA, 1993: Ética Pública y Derecho, Madrid: Real Academia de Ciencias Morales y Políticas, p. 32 .

${ }^{24}$ L. FerRAJOLI, Derecho y Razón, cit., p. 366. 
cambio, en los segundos una norma es válida cuando el acto de su producción está autorizado y regulado por otra norma superior del sistema ${ }^{25}$; de ahí que «la validez de una norma jurídica no pueda ser discutida sobre la base de que su contenido es incompatible con algún valor moral o político» ${ }^{26}$. Justo lo contrario ocurre en el Estado constitucional sustancial o rematerializado: la validez de sus normas puede ser discutida no sólo porque se hayan vulnerado las reglas de habilitación relativas al órgano y procedimiento de producción, sino también porque su contenido no se muestre conforme con lo prescrito por ciertos valores morales o políticos, porque mande o permita lo que no debería mandar o permitir y penetre en la esfera de lo indecidible, o porque no mande lo que sí debería mandar y penetre en la esfera de lo indecidible que no. Si puede decirse así, el Estado constitucional del garantismo descansa en un sistema jurídico también estático y no sólo dinámico ${ }^{27}$.

Este acercamiento entre el modo de ser del sistema jurídico y el modo de ser del sistema moral representa una muy fuerte tentación a la que pocos se resisten. La tentación, obvio es decirlo, consiste en impugnar una tesis central del positivismo, aquella que sostiene la separación conceptual entre el Derecho y la moral. Desde esta perspectiva, al menos allí donde existen Constituciones rematerializadas (es decir, de manera contingente y no conceptual) la tesis positivista conduce a la esterilidad de todo esfuerzo hermeneútico que no tenga presente esa feliz reconciliación entre el Derecho y la moral pública de la modernidad: el sistema jurídico genera legitimidad, fundamenta un autónomo deber de obediencia (a un Derecho que se supone que ya es justo, claro está) y reclama de los operadores jurídicos y en general de los juristas una actitud comprometida o militante con un Derecho positivo al fin preñado de moralidad ${ }^{28}$.

Más o menos esta es la tentación del constitucionalismo ético, una tentación a la que FERRAJOLI ha resistido como pocos, no cansándose de reiterar que «la doctrina ilustrada de la separación entre Derecho y moral constituye el presupuesto necesario de cualquier teoría garantista» ${ }^{29}$; doctrina que equivale a postular tanto la «laicidad del Derecho» como la «laicidad de la moral» ${ }^{30}$. Es más, el garantismo no sólo reposa en la autonomía de la moral, sino que reclama la «primacía del punto de vista externo» o crítico respecto del Derecho positivo, un punto de vista que impide «aquella variante del legalismo ético y del juspositivismo ideológico que sería el constitucionalismo ético» ${ }^{31}$.

${ }^{25}$ Véase H. Kelsen, 1960: Teoría pura del Derecho, trad. de J. Vernego, México: UNAM, 1986, pp. 203 y ss.

${ }^{26}$ H. Kelsen, 1944: Teoría General del Derecho y del Estado, trad. de E. GARCíA MAYNEZ, México: UNAM, 1979, p. 133.

${ }_{27}$ Más concretamente, «el fundamento de la vigencia es siempre y solamente formal y nomodinámico, mientras que el de la validez es al mismo tiempo nomodinámico en su aspecto formal y nomoestático en cuanto a su aspecto sustancial», Principia Iuris, $\$ 9.17$, vol. I, p. 568.

${ }^{28}$ Intenté una aproximación crítica a esta derivación del constitucionalismo contemporáneo en 1997: Constitucionalismo y positivismo, México: Fontamara, pp. 49 y ss.

${ }^{29}$ L. FERRAJOLI, Derecho y razón, cit., p. 231.

${ }^{30}$ Y que supone su recíproca autonomía: «por un lado, el principio en virtud del cual el Derecho no debe ser nunca utilizado como instrumento de mero reforzamiento de la (esto es, de una determinada) moral, sino únicamente como técnica de tutela de intereses y necesidades vitales; por otro, el principio, inverso y simétrico, por el cual la moral, si cuenta con una adhesión sincera, no requiere, sino que más bien excluye y rechaza, el soporte heterónomo y coercitivo del Derecho», L. FERRAJOLI, Garantismo. Una discusión sobre derecho y democracia, cit., p. 17.

${ }^{31}$ L. FERRAJOLI, «Juspositivismo crítico y democracia constitucional», cit., p. 19. 
En este punto la discrepancia con el neoconstitucionalismo resulta patente en Principia Iuris desde la misma Introducción: «la autonomía del punto de vista externo» cierra el paso «a las dos opuestas confusiones entre Derecho y moral presentes en gran parte del moderno "neo-constitucionalismo": a la confusión del Derecho con la moral operada por las distintas versiones del iusnaturalismo; a la confusión de la moral con el Derecho operada por las distintas versiones del legalismo ético y en particular por la del constitucionalismo ético ${ }^{32}$. Nada, pues, de una complaciente asunción de las opciones morales y políticas del Derecho como horizonte último de una ética pública, nada de presunciones de justicia en favor de la legalidad, incluida la legalidad democrática, nada, en fin, de fundamentos morales en favor de la obligación jurídica.

A mi juicio, este saludable distanciamiento moral respecto del Derecho representa una de las peculiaridades más valiosas del constitucionalismo de FERRAJOLI. Y es que, aunque sea muy consciente de que el criterio estático o sustantivo del que antes hemos hablado ofrece un cierto parecido de familia con el iusnaturalismo ${ }^{33}$, FERRAJOLI considera que aun la más óptima forma de organización política no deja de ser una utopía de Derecho positivo que jamás será realizable a la perfección ${ }^{34}$. El argumento no expresa ninguna opinión intuitiva o caprichosa, sino que responde a una concepción profunda a propósito de la naturaleza del Estado y de las instituciones. Como manifestación de la Ilustración consecuente, para el constitucionalismo garantista el Derecho y su fuerza son un mal, acaso un mal necesario, pero un mal al fin y al cabo, que conserva siempre un irremediable residuo de ilegitimidad y, por tanto, una necesidad de justificación ante una instancia superior, que es justamente la moral, siempre crítica y externa al Derecho positivo. Todos los totalitarismos comportan una visión optimista del poder; «por el contrario, el presupuesto del garantismo es siempre una concepción pesimista del poder como malo, sea quien fuere quien lo posee, puesto que se halla expuesto en todo caso, a falta de límites y garantías, a degenerar en despotismo» ${ }^{35}$.

Creo que esta concepción de las instituciones se halla en el núcleo mismo de la filosofía contractualista de la que el constitucionalismo es legítimo heredero: el Estado no se concibe aquí como un hecho natural que hayamos de aceptar como un designio divino, sino que es «un fenómeno artificial y convencional, construido por los hombres para tutelar sus necesidades y derechos naturales [...] lo que es natural no es el Derecho o el Estado, sino la ausencia del derecho y el estado de naturaleza» ${ }^{36}$. De ahí que pueda hablarse de una «irreductible ilegitimidad política del poder en el Estado de derecho [...] Garantismo y democracia son siempre, en efecto, modelos normativos imperfectamente realizados y valen por tanto, además de como parámetros de legitimación, también como parámetros de deslegitimación política» ${ }^{37}$. El Derecho, todo

32 Principia Iuris, cit., Introducción, 4, vol. I, p. 17. En la nota 25 de la Introducción cita los nombres de R. AleXY, R. DWORKIN y C. NINO como representantes de un constitucionalismo «tendencialmente iusnaturalista», vol. I, p. 74.

33 L. FERRAJOLI, «Juspositivismo crítico y democracia constitucional», cit., p. 7.

34 Ibidem, p. 14.

35 L. FERRAJOLI, Derecho y razón, cit., p. 885. «Mi pesimismo - ha matizado recientemente- no se refiere en absoluto al Derecho y las instituciones, sino únicamente al poder», siempre desbordante respecto al Derecho, Garantismo. Una discusión sobre derecho y democracia, p. 37.

${ }^{36}$ L. FERRAJOLI, «Juspositivismo crítico y democracia constitucional», cit., p. 15.

37 L. FERRAJOLI, Derecho y razón, cit., pp. 886 y ss. 
Derecho, en cuanto que antinatural y orientado a la consecución de fines se halla siempre necesitado de justificación, precisamente a la luz de una moral que es externa al Derecho mismo y que toma cuerpo en los derechos fundamentales. Por muchos que sean los valores morales incorporados por el constitucionalismo rematerializado, éste nunca pierde su fondo de ilegitimidad y, por ello, nunca puede desvanecerse la tensión crítica a la que nos invita la ilustrada primacía del punto de vista externo; tensión crítica que no sólo ha de mantener el observador externo, sino la propia ciencia del Derecho. Lejos del jurista complaciente con el Derecho positivo, lejos del jurista beato de la democracia representativa, el garantismo propugna una ciencia jurídica crítica y comprometida, pero comprometida con la efectividad de los derechos fundamentales.

\section{LA DISOCIACIÓN ENTRE VIGENCIA Y VALIDEZ. EL PROBLEMA DE LAS LAGUNAS Y DE LAS ANTINOMIAS}

Si la separación entre el ser y el deber ser externo del Derecho es la aportación y el rasgo característico del positivismo, la separación entre el ser y el deber ser interno del Derecho lo es del constitucionalismo ${ }^{38}$. La disociación entre vigencia y validez, que es reflejo de esta última separación, constituye uno de los argumentos centrales de Principia Iuris en cuanto que teoría del Derecho del Estado constitucional. De ahí el papel central que desempeñan las lagunas y las antinomias o, si se prefiere, el problema de la plenitud y de la coherencia del ordenamiento ${ }^{39}$ : las lagunas son vicios por omisión y suponen la indebida omisión de una norma cuya producción resulta obligada por otra norma superior, por ejemplo por un precepto constitucional relativo a derechos fundamentales ${ }^{40}$; las antinomias son vicios por comisión y suponen la indebida producción de una norma que viene prohibida justamente por hallarse en contradicción con otra superior, en particular con una norma constitucional que regula su producción ${ }^{41}$. En suma, la fuerza normativa de la Constitución se juega en este capítulo, una fuerza que puede verse frustrada tanto por acción como por omisión, ya que la existencia de lagunas y de antinomias convierte en inaplicables y por tanto en ineficaces a las propias normas constitucionales: estas últimas encarnan un «deber ser» jurídico que, sin embargo, se ve desmentido por su «ser» legal.

Ciertamente, las lagunas y las antinomias generan una obligación de repararlas dirigida a la autoridad competente mediante la anulación o la derogación de la norma indebidamente existente o la introducción de aquella indebidamente inexistente. Ahora bien, mientras esto no suceda, la Constitución deviene inaplicada: inaplicada bien porque falta la norma necesaria para su realización, bien porque existe una norma legal (ésta sí aplicable) que desvirtúa su contenido normativo. Este parece ser «un rasgo co-

38 Principia Iuris, Introducción, 6, vol. I, pp. 26 y ss.

39 «Un problema central de la democracia constitucional», Principia Iuris, $\ 10.19$, vol. I, p. 684.

${ }^{40}$ Parece obvio que este concepto de laguna no se ajusta al tradicional, donde por laguna se entiende simplemente la ausencia de una norma adecuada para regular un cierto caso, no de una norma requerida por otra norma del sistema.

${ }^{41}$ Tampoco el concepto de antinomia se ajusta por completo al tradicional. Las antinomias que preocupan a FERRAJOLI, las antinomias en «sentido estricto», son aquellas contradicciones que aparecen entre normas de distinto grado jerárquico; no las que surgen entre normas de la misma jerarquía y que pueden resolverse mediante el criterio cronológico o el de especialidad. 
mún a todos los vicios, sean formales o sustanciales, comisivos u omisivos» y es que «no pueden ser eliminados ni reparados si no es mediante una específica decisión, en observancia, justamente, de la norma por ella inobservada» ${ }^{42}$. Podrá tratarse de una sentencia de anulación, de una disposición derogatoria o, en el caso de las lagunas, de la introducción del acto cuya omisión supone una inobservancia. Pero de lo que no podrá tratarse en ningún caso es de un acto interpretativo o de mera aplicación del Derecho. Aquí lo que se requiere no es una interpretación de las normas existentes, sino la producción de una nueva norma que colme la laguna o que ponga fin a la antinomia: «antinomias y lagunas en el sentido aquí definido no son inmediatamente solventables por el intérprete, a quien no compete la alteración del derecho vigente aplicable aun cuando ilegítimo. Requieren, en efecto, para ser removidas, la intervención de específicos actos decisionales: precisamente, la anulación de las decisiones inválidas o la introducción de las decisiones que faltan» ${ }^{43}$.

Este carácter de «vicios» se refleja en los llamados «criterios» de resolución. Las antinomias y lagunas «tradicionales» — que FERRAJOLI llama débiles— no encierran ningún vicio y encuentran su solución en metanormas constitutivas, en cuanto tales inviolables, como son la analogía o el criterio cronológico y el de especialidad, de las que bien puede hacer uso el intérprete. Por el contrario, los vicios de los que aquí hablamos sólo pueden superarse mediante el criterio jerárquico, que es una metanorma deóntica o regulativa. En suma, los principios de plenitud y coherencia son principios lógicos del Derecho, pero no en el Derecho, «no estando expresados por normas jurídicas»; no son principia iuris et in iure, sino principia iuris tantum ${ }^{44}$. Es el triunfo de la positividad: las normas constitucionales establecen sólo un deber ser, por ejemplo el deber ser de dictar una ley o el deber ser de no dictarla, o de eliminar alguna vigente. Pero, mientras no se cumple esa obligación por parte del legislador, la que viene inaplicada en realidad es la propia Constitución.

Comenzando por las lagunas, conviene advertir también que FERRAJOLI mantiene una concepción bastante estricta de la tarea jurisdiccional, que «consiste siempre en la garantía secundaria de la obligación de anular los actos inválidos o de la condena de los actos ilícitos» ${ }^{45}$, es decir, por lo que se refiere a los actos inválidos, presenta siempre un contenido negativo o de anulación. Muy lógico parece por tanto que la jurisdicción no pueda remediar una laguna, algo que, por definición, requiere la producción de una nueva norma, justamente de aquélla reclamada por la Constitución y que ha sido indebidamente omitida.

En realidad, la posición de FERRAJOLI a propósito de las lagunas creo que puede dar pie a dos interpretaciones, una más radical o severa y otra más moderada, pero ambas no del todo acordes ni con la práctica del constitucionalismo contemporáneo ni con las construcciones teóricas neoconstitucionalistas, generalmente abiertas a un cierto activismo judicial que deposita en los aplicadores del Derecho la responsabilidad de actuar la Constitución incluso asumiendo tareas cuasi legislativas. La primera interpretación se traduciría en una revitalización del principio de la interpositio legisla-

\footnotetext{
${ }^{42}$ Principia Iuris, $\$ 9.12$, vol. I, p. 545.

43 Ibidem, $\mathbb{S} 10.19$, vol. I, p. 687.

${ }^{44}$ Ibídem, Introducción, 6, vol. I, p. 28.

${ }^{45}$ Ibidem, $\$ 11.17$, vol. I, pp. 817-818.
} 
toris: las cláusulas materiales de la Constitución y, en particular, los derechos fundamentales tienen fuerza normativa, generan obligaciones, pero en principio sólo frente al legislador; para que un juez ordinario pueda resolver un caso a la luz de la Constitución, es decir, para que ésta resulte aplicable, es precisa una legislación de actuación. No cabe deducir de modo directo deberes u obligaciones a partir de derechos fundamentales porque todas las garantías, tanto primarias como secundarias, han de ser previamente diseñadas por el legislador, es decir, han de estar «puestas». Algún pasaje de Principia Iuris parece avalar esta interpretación: los derechos fundamentales «requieren siempre, como primer y prejudicial cumplimiento, una legislación de actuación, primaria y secundaria, que introduzca las correspondientes garantías, respectivamente primarias y secundarias»; algo que ocurre no sólo con los derechos sociales, siempre necesitados de desarrollo, sino también «con los derechos individuales, tanto civiles como de libertad, los cuales exigen la introducción de las respectivas prohibiciones» ${ }^{46}$. De este modo, si he entendido bien, en ausencia por ejemplo de una ley de huelga que imponga al empresario la prohibición de despido de los trabajadores por incumplimiento de contrato, estaríamos ante una laguna de garantías primarias y resultaría que el precepto constitucional sería inaplicable y por tanto ineficaz para tutelar la conducta huelguista.

Pues bien, si es esto lo que se quiere decir, la posición de FERRAJOLI resultaría de una insoportable rigidez para el neoconstitucionalismo, que defiende con todo vigor la tesis de la aplicación directa e inmediata de la Constitución y muy especialmente de sus derechos de libertad. Es verdad que la Constitución puede necesitar inexcusablemente una legislación de desarrollo, por ejemplo cuando «anuncia» instituciones o servicios públicos (segunda hipótesis que veremos de inmediato), pero sus principios y derechos resultan inmediatamente operativos aun sin normativa de desarrollo. En palabras de un muy influyente autor español: «la Constitución (tiene) un valor normativo y vinculante directo»; «es una norma jurídica efectiva, por tanto aplicable por sí misma»; un derecho fundamental «tiene el carácter de Derecho directamente aplicable, sin necesidad del intermedio de una Ley» ${ }^{47}$. Esta es una tesis arraigada en el seno del constitucionalismo y, como dice GUASTINI, representa uno de los elementos esenciales del proceso de constitucionalización: «la idea de que toda norma constitucional —independientemente de su estructura o de su contenido normativo- es una norma jurídica genuina, vinculante y susceptible de producir efectos jurídicos» ${ }^{48}$.

Un ejemplo de la jurisprudencia española. El art. 30.2 de la Constitución dice así: «La ley fijará las obligaciones militares de los españoles y regulará, con las debidas garantías, la objeción de conciencia así como las demás causas de exención del servicio militar obligatorio, pudiendo imponer, en su caso, una prestación social sustitutoria». En ausencia de una normativa de actuación, nos hallamos muy probablemente ante una laguna en el sentido de FERRAJOLI: primero, porque el propio precepto constitucional se remite a una futura ley que establezca las «debidas garantías»; segundo, porque anun-

${ }^{46}$ Ibídem, $\ 13.15$, vol. II, pp. 78-79. Esta necesidad de una «legislación de actuación» obedece al carácter nomodinámico del Derecho, donde la existencia de una norma no puede ser deducida a partir de otra norma, «sino inducida, como hecho empírico, del acto de su producción», ibídem, \$12.14, vol. I, p. 916.

${ }^{47}$ E. GARCÍA DE ENTERRÍA, 1980: «La Constitución como norma jurídica», en A. PREDIERI y E. GARCÍA DE ENTERRÍA (eds.) La Constitución española de 1978. Estudio sistemático, Madrid: Civitas, pp. 111 y 121.

${ }^{48}$ R. Guastini, «La “constitucionalización” del ordenamiento jurídico: el caso italiano», cit., p. 158. 
cia una «prestación social sustitutoria» que requiere la organización de un servicio público; y tercero, porque es la primera vez que en el ordenamiento español aparece la expresión «objeción de conciencia», por lo que en 1978 carecía de un significado preciso decantado por la tradición al que el juez pudiera acudir. ¿Significó esta laguna la imposibilidad de aplicar directamente la norma constitucional y por consiguiente de ejercer el derecho? La STC 15/1982, a propósito de un supuesto de objeción anterior a la promulgación de la ley de desarrollo, ofrece una respuesta negativa: «El que la objeción de conciencia sea un derecho que para su desarrollo y plena eficacia requiera la interpositio legislatoris no significa que sea exigible tan sólo cuando el legislador lo haya desarrollado, de modo que su reconocimiento constitucional no tendría otra consecuencia que la de establecer un mandato dirigido al legislador sin virtualidad para amparar por sí mismo pretensiones individuales». En otras palabras, el derecho fundamental, además de generar una obligación dirigida al legislador para que resuelva la laguna de garantías primarias y secundarias, genera también algunas obligaciones directas, es decir, al menos aquellas garantías primarias que son indispensables para la existencia del Derecho.

Sin embargo, aunque FERRAJOLI insiste en que las lagunas son «imposibles de resolver por el intérprete en el marco del Derecho vigente» ${ }^{49}$, lo cierto es que en algunos pasajes de Principia Iuris esta es una cuestión que parece depender del Derecho positivo, que bien puede establecer a través de una cláusula general o por vía interpretativa al menos las garantías primarias de los respectivos derechos, es decir, las obligaciones dimanantes o que son reflejo de los derechos constitucionales. Así sucedió en la Constitución francesa del Año III ${ }^{50}$ o sucede hoy al amparo de la doctrina de la Corte constitucional italiana, que ha reconocido (al igual que hizo más tarde la española) el carácter inmediatamente preceptivo de todas las normas constitucionales. «Pero esto no es en verdad suficiente para colmar las lagunas ${ }^{51}$. Ahora bien, al margen de que ahora parece aceptarse lo que antes se ha negado, es decir, que por vía interpretativa se puedan colmar las lagunas, tal vez la pregunta que procede formular es qué tipo de lagunas pueden resolverse directamente por los jueces y cuáles en cambio requieren necesariamente la interposición del legislador, naturalmente en el marco del constitucionalismo actual. Tal vez la segunda interpretación que antes anunciábamos nos ayude a responder.

La posición de FERRAJOLI admite en efecto una interpretación más moderada, según la cual los contenidos sustantivos de la Constitución gozarían de inmediata fuerza normativa, dando lugar a obligaciones directamente exigibles por el juez ordinario, por ejemplo en un asunto civil o en el enjuiciamiento de un acto o disposición administrativa; esto es, algunas garantías primarias serían aplicables aun en el supuesto de laguna legal. Y es que «no todo vicio, en efecto, da lugar a antinomias o a lagunas [...] no es una laguna cualquier incumplimiento de actos prescriptitos. La razón es simple: los vicios formales y los vicios sustanciales que no implican normas sino situaciones

49 Principia Iuris, cit., $\mathbb{\$} 10.19$, vol. I, p. 685.

${ }^{50}$ Que establecía en el art. 1 del capítulo «Deberes» que «la Declaración de derechos contiene las obligaciones de los legisladores»; previsión que en verdad parece algo modesta como para predicar que con ella quedaban colmadas las lagunas de garantías, siquiera primarias.

51 Principia Iuris, cit., $\$ 10.16$, vol. I, p. 675. 
singulares dan lugar a prescripciones que, a causa de su singularidad, no entran a formar parte del ordenamiento ${ }^{52}$. En otras palabras, lo que al parecer sucedería es que esa aplicación directa de los derechos sólo podría tener efectos negativos o de anulación (del despido del trabajador huelguista, de la sanción al joven objetor de conciencia), es decir, daría lugar a situaciones singulares, nunca efectos positivos o de creación normativa. Esto parece evidente en algunas lagunas: cuando la garantía de un derecho reclama una protección penal, es obvio que el juez no puede producir un nuevo tipo delictivo, que sería contrario al principio de estricta legalidad penal; y lo mismo cabe decir cuando dicha garantía requiere la organización de un servicio público, sanitario, educativo o similar; o, en fin, cuando exige el establecimiento de una institución, como durante bastantes años ocurrió con el jurado en España o con el Tribunal Constitucional en Italia. Pero parece cierto también que en situaciones singulares de aplicación del Derecho el intérprete puede salvar las lagunas de garantías primarias, imputando directamente las obligaciones o prohibiciones que son «reflejo» del derecho fundamental; puede considerar por ejemplo que, aunque ninguna ley lo establezca, la Constitución basta para que el trabajador huelguista no sea despedido ni el objetor sancionado.

En cualquier caso, la práctica del constitucionalismo tampoco acepta pacíficamente una concepción tan rigurosa de la función jurisdiccional como instancia sólo anuladora, y así se encarga de recordarlo el propio FERRAJOLI ${ }^{53}$. En particular, las sentencias llamadas aditivas o manipulativas suponen una legislación positiva en la medida en que extienden una cierta disciplina normativa a favor de personas o supuestos inicialmente no contemplados en la norma. Herramienta fundamental al servicio del principio de igualdad, estas sentencias, con todas las limitaciones que se quiera, suponen una judicialización de la tarea garantista consistente en colmar las lagunas. Y, por cierto, no veo ninguna dificultad para que esta técnica «antilagunas» (tal vez bajo los ropajes del argumento analógico) sea usada por el juez ordinario en aplicación directa del principio de igualdad.

Aparentemente la función judicial resulta de mayor protagonismo en presencia de antinomias dado que la resolución de éstas requiere, no una legislación positiva como en el caso de las lagunas, sino una actividad negativa o anuladora; si la jurisdicción tan sólo podía constatar las lagunas, parece en cambio que puede constatar y resolver las antinomias. La existencia de una ley inconstitucional genera en efecto una obligación alternativa: su derogación por el Parlamento o su anulación por el juez de constitucionalidad. Sin embargo, antinomias y lagunas presentan un rasgo común y es que ninguna de ellas admite una respuesta interpretativa, es decir, ninguna puede ser resuelta por el juez ordinario, en el caso de las antinomias justamente mediante la pura y simple desaplicación de la norma ilegítima; con lo cual, como ya sabemos, viene desaplicada la propia Constitución. De nuevo es necesario un «legislador negativo» (el Parlamento o el Tribunal Constitucional) que derogue o anule la norma inconstitucional.

No queda claro, a mi juicio, si ésta pretende ser una tesis teórica o sólo una tesis dogmática dependiente, por tanto, de las determinaciones del Derecho positivo. En

\footnotetext{
${ }^{52}$ Ibidem, $\$ 10.19$, vol. I, p. 687.

53 Ibidem, \$ 13.19, vol. II, pp. 97-98.
} 
algunos pasajes parece sugerirse lo primero, sobre todo cundo se afirma la existencia de una diferencia estructural entre los criterios cronológico y de especialidad y el criterio jerárquico de resolución de antinomias ${ }^{54}$, pero creo que debemos acoger la segunda interpretación: que las antinomias impliquen la desaplicación de la Constitución a favor de la norma contradictoria (mientras ésta no sea derogada o anulada, claro está) es una característica propia de los llamados sistemas de jurisdicción concentrada ${ }^{55}$, pero no de los sistemas de jurisdicción difusa. Por ello FERRAJOLI se ve en la necesidad de acuñar un género especial de antinomias a las que denomina como «débil-fuerte». Son débiles aquellas antinomias que encuentran respuesta en los criterios cronológico y de especialidad y que pueden ser resueltas directamente por el intérprete aplicando la norma posterior o la norma especial; son fuertes, en cambio, las antinomias que ahora interesan, aquellas que reclaman la consideración del criterio jerárquico, al parecer inaccesible al intérprete. Pues bien, la antinomia débilfuerte representa un tertium genus «intermedio respecto a las antinomias en sentido fuerte y en sentido débil porque en ellas, al igual que en las primeras, existe un vicio que sin embargo, como en las segundas, es directamente superable mediante la aplicación de la norma superior y la desaplicación de la inferior, dejada en vigor aun cuando reconocida inválida». Así sucede — añade - en muchos ordenamientos americanos y también en el italiano (y en el español) en relación con los reglamentos inválidos que, al margen de que también puedan ser anulados, deben en todo caso ser desaplicados ${ }^{56}$.

Pero entonces, si no me equivoco, parece que la única diferencia entre las antinomias fuertes y las débiles-fuertes reside en su forma de resolución (anulación/desaplicación) y ésta a su vez en la libre opción de los distintos ordenamientos. Con lo cual procede preguntase cuál de los dos sistemas resulta preferible desde el punto de vista de la eficacia del Estado constitucional y de la vigencia de los derechos fundamentales. Para FERRAJOLI, «sin duda», resulta más eficaz el sistema kelseniano o europeo de la anulación que el norteamericano de la desaplicación: primero, por la menor separación orgánica del Tribunal Supremo norteamericano respecto de las instituciones de gobierno; y segundo, por los mayores espacios de discrecionalidad de los que goza este último, lo que se traduce en indeterminación y en una rebaja de garantías $^{57}$.

Esta opción a favor del modelo europeo es discutible ${ }^{58}$, pero, al margen de preferencias, revela las fuertes reservas del constitucionalismo garantista hacia la deriva judicialista propia del neoconstitucionalismo. De entrada, no está de más recordar que el diseño kelseniano de una jurisdicción concentrada respondió de modo explícito al propósito de conjurar los riesgos de un excesivo protagonismo judicial, al que pre-

\footnotetext{
${ }^{54}$ Así en el punto 3 de la Introducción o en algunos fragmentos de los capítulos 10.19 y 12.13 de Principia Iuris, vol. I, pp. 12 y ss.; pp. 684 y ss.; pp. 908 y ss.

55 Así se reconoce expresamente en el punto 3 de la Introducción: en los ordenamientos «dotados de constitución rígida y de control concentrado de constitucionalidad, la solución del conflicto entre normas de distinto nivel no puede ser obtenida directamente por el intérprete», vol. I, p. 13.

56 Principia Iuris, $\mathbb{S} 10.19$, vol. I, pp. 689-690.

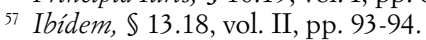

58 Por mi parte, he defendido la superioridad del sistema difuso en 2003: Justicia constitucional y derechos fundamentales, Madrid: Trotta, pp. 168 y ss.
} 
suntamente hubiera conducido en Europa la implantación del modelo norteamericano de jurisdicción difusa, en detrimento de una democracia parlamentaria que en verdad no pasaba por sus mejores momentos ${ }^{59}$. En realidad, cabe decir que el rechazo kelseniano a la incorporación de principios sustantivos al texto constitucional y su diseño de una jurisdicción concentrada responden a la misma preocupación: evitar el activismo judicial y defender las prerrogativas del Parlamento. Pero es que, además, la imagen de un control judicial de constitucionalidad por vía desaplicativa tampoco queda muy bien parada en Principia Iuris: el problema de las antinomias, que lesionan la propia estructura de la democracia constitucional y del Estado de derecho, se manifiesta en la «regresión a un Derecho jurisprudencial de tipo premoderno, que amenaza con arrasar el completo orden de la democracia constitucional» ${ }^{60} ; \mathrm{y}$, en fin, a la hora de tomar partido por el modelo kelseniano, no deja de recordar los episodios de «gobierno de los jueces» y de jurisprudencia conservadora o antisocial que registra la historia del Tribunal Supremo norteamericano ${ }^{61}$. En suma, la posición de FERRAJOLI resulta también en este punto poco proclive a la vocación judicialista del neoconsitucionalismo.

Sin embargo, tal vez lo más llamativo de la práctica del constitucionalismo europeo de posguerra y uno de los hallazgos más celebrados del judicialismo neoconstitucionalista haya consistido precisamente en abrir la posibilidad de una jurisdicción difusa en el entramado institucional de un modelo de jurisdicción concentrada, algo que FERRAJOLI por supuesto no contempla. Dicho más claramente: en la posibilidad de ensayar técnicas desaplicadoras de la ley en sistemas que reservan el control de constitucionalidad a un Tribunal Constitucional separado de la jurisdicción ordinaria. En línea de principio, como sabemos, el juez nunca puede negarse a aplicar la ley y, si duda de su constitucionalidad, ha de plantear la correspondiente cuestión o pregunta para que sea el Tribunal Constitucional quien decida mediante una sentencia que, en su caso, tendrá los efectos generales de la anulación, no los particulares de la desaplicación. Pero esto sólo en vía de principio.

Básicamente, esta operación de ingeniería judicial comprende los siguientes pasos: primero, obviamente, no poner en duda la constitucionalidad de la ley, algo que obligaría a plantear la cuestión. Segundo, considerar sin embargo que resulta injusta o inadecuada para regular el caso al implicar (insisto: en el caso) un sacrificio desproporcionado de algún principio o derecho fundamental relevante. Tercero, construir un conflicto de principios o derechos; concretamente un conflicto entre los principios o derechos que están detrás de la ley, que se ven satisfechos o realizados por ésta, y aquellos otros en pugna que aparecen sacrificados. Cuarto, argumentar a partir de las reglas de la ponderación. Y quinto, finalmente, aplicar directamente el precepto constitucional triunfante (en el caso) con la consiguiente desaplicación del precepto derrotado y de la ley dictada a su amparo. Pero con ello entramos ya en la última de las discrepancias entre FERRAJOLI y el neoconstitucionalismo.

\footnotetext{
59 Me permito remitir nuevamente al trabajo citado en nota anterior, pp. 80 y ss.

${ }^{60}$ Principia Iuris, cit., $\mathbb{\$} 13.15$, vol. II, p. 80.

${ }^{61}$ Así en las notas 106 y 107 del $\$ 13.18$ de Principia Iuris, vol. II, pp. 141-142.
} 


\section{LA DISOCIACIÓN DEL DEBER SER JURÍDICO. EL PROBLEMA DE LOS CONFLICTOS DE DERECHOS}

Si el positivismo se basaba en la disociación entre deber ser moral y ser jurídico, y si el constitucionalismo lo hace en la disociación entre validez y vigencia, o sea entre el deber ser jurídico (validez) y el ser también jurídico (vigencia), el neoconstitucionalismo parece responder a una nueva disociación, esta vez, por paradójico que parezca, en la esfera del propio deber ser jurídico. El positivismo anunciaba un conflicto externo, el que se produce entre Derecho y moral; el constitucionalismo anuncia un conflicto interno entre los distintos escalones del sistema, básicamente el que se produce entre Constitución y ley, y que da lugar a los fenómenos ya comentados de las lagunas y de las antinomias. El neoconstitucinalismo se vincula a otro episodio de conflicto aún más interno que se verifica en el seno mismo de las normas sustantivas de la Constitución. FERRAJOLI, que es perfectamente consciente de los dos primeros conflictos, hasta el punto de hacer de ellos el argumento central de su concepto (separación entre Derecho y moral) y de su teoría (separación entre validez y vigencia) del Derecho, se muestra sumamente cauto frente a este último conflicto, incluso a veces abiertamente contrario a su consideración. Aquí se aprecia una nueva discrepancia entre el constitucionalismo de FERRAJOLI y las más usuales presentaciones del neoconstitucionalismo, que acaso hacen de las colisiones entre preceptos sustantivos de la Constitución la más destacada seña de identidad del sistema jurídico constitucionalista; tal vez en ocasiones con alguna exageración.

Ante todo, conviene advertir que en algunas doctrinas neoconstitucionalistas se sostiene de modo explícito que los textos constitucionales no son como las leyes, y ello no sólo en el obvio sentido formal de ostentar una jerarquía superior, sino en un sentido más morfológico o estructural que afecta a su propia forma de ser. Las leyes son la expresión de un momento político unitario o monolítico, la expresión de una mayoría parlamentaria que, mejor o peor, responde a una determinada concepción moral y política. Por supuesto, también existen contradicciones entre las leyes, pero éstas se resuelven básicamente según un criterio cronológico. No ocurre así con las Constituciones, al menos con las que rigen hoy en Europa; ellas pretenden expresar una coexistencia de proyectos políticos posibles que se traduce en una coexistencia de principios plurales y tendencialmente contradictorios, algo que afecta también y de modo sobresaliente al corazón mismo de su normativa material, que son los derechos fundamentales. Creo que este es el argumento principal que recorre todo el planteamiento de ZAGREBELSKY y me parece en lo esencial acertado para dar cuenta de lo que sucede en algunas Constituciones, como por ejemplo la española, que precisamente se quiso presentar como una Constitución de «consenso» que integraba (pero que no siempre logró conjugar armónicamente) valores y principios políticos de distinta procedencia. Su lema bien pudiera ser «del carácter monolítico de la ley al pluralismo constitucional». La Constitución pluralista no es ni un mandato ni un contrato y, por eso, ni la teoría de la interpretación de la ley ni la del contrato resultan satisfactorias: no hay voluntad constituyente que pueda ser tratada como intención del legislador, ni siquiera de unas partes que llegan a un acuerdo. Lo que hay son «principios universales, uno junto a otro según las pretensiones de cada parte, pero faltando la regulación de su compatibilidad, la solución de las "colisiones" y la fijación de los puntos de equi- 
librio» ${ }^{62}$; se produce, pues, lo que se ha llamado una pluralidad de «mundos constitucionalmente posibles» ${ }^{63}$.

La cuestión no tendría mayor trascendencia si las Constituciones se conformasen con ser documentos políticos sin fuerza normativa, una vistosa colección de principios morales y buenas intenciones destinada a la «libre interpretación» por parte de las sucesivas mayorías de gobierno. Pero las cosas no son así: las Constituciones hoy no sólo tienen una fuerza normativa indiscutible, sino que, merced a su rematerialización, ofrecen soluciones o, cuando menos, orientaciones de sentido en las más variadas esferas de relación jurídica. Esto es lo que se ha dado en llamar efecto impregnación o irradiación ${ }^{64}$, que justamente significa el desbordamiento de un Derecho constitucional que ahora inunda el conjunto del ordenamiento; ya no se trata sólo de regular las relaciones entre los poderes del Estado, sino que casi podría decirse que todo conflicto jurídico, desde el horario de las panaderías al etiquetado del chocolate ${ }^{65}$, encuentra alguna respuesta constitucional. Pero, si esto es así, la imagen de las tres esferas que propone FERRAJOLI en parte se desvanece: ya no cabe hablar del ámbito de lo decidible como si éste fuera un mundo de absoluta libertad para el legislador democrático, pues, como se ha dicho, la Constitución satura todo el sistema de una normatividad supralegal; y acaso tampoco las esferas de lo indecidible y de lo indecidible que no presenten unas fronteras tan impenetrables como se sugiere, dado que muchas veces la Constitución no nos habla con una sola voz. Porque, ¿qué es lo que cabe encontrar en la Constitución y en su catálogo de derechos fundamentales? Pues sólo algunas veces respuestas categóricas y concluyentes; con frecuencia, únicamente es posible recabar de ella razones tendencialmente conflictivas. Así, para seguir con nuestro ejemplo, una ley que limite el horario de trabajo nocturno en las panaderías podrá alegar en su favor razones justificatorias (la salud de los trabajadores, el derecho al descanso), pero también habrá de superar otras razones en contra (la libertad negocial de las partes, el derecho del empresario a organizar el trabajo). Si volvemos la mirada a la labor encomendada por el garantismo a los jueces y a la propia ciencia del Derecho resulta que la esfera donde ha de desarrollarse su tarea depuradora ya no resulta tan clara ni perfilada.

Todo ello tiene que ver con un rasgo típico del constitucionalismo contemporáneo, que es la naturaleza «principial» de sus normas sustantivas. Mucho se ha discutido sobre la diferencia entre reglas y principios y no es cuestión de volver sobre el tema, pero,

62 G. Zagrebelsky, 1998: «Storia e costituzione», en G. ZagrebelsKy, P. PortinARO y J. Luther (eds.), Il futuro della costituzione, Torino: Einaudi. Tal vez esto explique por qué el originalismo y la extraordinaria importancia que se concede en Estados Unidos a las intenciones del constituyente resultan en cambio de muy escasa relevancia en Europa.

${ }^{63}$ La expresión es de J. J. MORESO, 1997: La indeterminación del Derecho y la interpretación de la Constitución, Madrid: CEPC, p. 167.

${ }^{64} \mathrm{El}$ «efecto irradiación» (Ausstrablungswirkung) suele aludir en la doctrina alemana a la eficacia o proyección de los derechos fundamentales en el ámbito del Derecho privado. Aquí se usa en un sentido más general. De impregnación habla R. GUASTINI en «La "constitucionalización” del ordenamiento jurídico: el caso italiano», cit., pp. 153 y ss.

${ }^{65}$ Ambos ejemplos pertenecen a la jurisprudencia alemana y puede verse su comentario, respectivamente, en M. BOROWSKI, 2003: La estructura de los derechos fundmentales, trad. de C. BERNAL, Bogotá: Universidad Externado de Colombia, pp. 5 y ss., y R. AleXY, 2002: «Epílogo a la Teoría de los derechos fundamentales», trad. de C. BERnAL, Revista Española de Derecho Constitucional, 66, p. 28. 
con independencia de si existe o no una diferencia fuerte o cualitativa, en lo que parece alcanzarse cierta unanimidad es en que la idea de principios adquiere toda su virtualidad jurídica en el marco de los conflictos normativos ${ }^{66} \mathrm{y}$, más concretamente, de los conflictos normativos intraconstitucionales: decimos que las normas son principios cuando sus colisiones no se saldan con la pérdida de validez de uno de ellos, ni tampoco mediante la configuración de uno como excepción permanente al otro (según la regla de la especialidad), sino con un triunfo que pudiéramos llamar circunstancial y que se decide a través de ponderación; así, entre la libertad ideológica y la cláusula de orden público (que en la Constitución española figura como un límite expreso, art. 16.1) no se advertiría una frontera nítida, de modo que, vulnerado el orden público, dejase de actuar sin más la tutela iusfundamental, sino que cabe perfectamente que una misma conducta sea prima facie y simultáneamente ambas cosas (ejercicio de la libertad religiosa y alteración del orden público), debiendo triunfar en definitiva el Derecho o su límite según el peso de cada uno de ellos en el caso concreto. Por eso habla GUASTINI de una «jerarquía móvil» ${ }^{67}$. Este es el núcleo del juicio de ponderación ${ }^{68}$ y es el núcleo también de toda una concepción de los derechos fundamentales y de sus posibles restricciones ${ }^{69}$.

Pues bien, FERRAJOLI muestra muy poca simpatía hacia esta visión conflictualista de la Constitución y de los derechos fundamentales. Aun cuando no deja de reconocer algunos supuestos de conflicto entre derechos, así como la idoneidad del juicio de ponderación como forma de resolverlos ${ }^{70}$, considera que la cuestión se ha dramatizado en exceso por parte del neoconstitucionalismo, inventando conflictos allí donde sólo hay límites y lesionando con ello la propia normatividad y supremacía constitucional. Porque esta es una cuestión teórica, pero no carente de un importante trasfondo político o de política jurídica. El excesivo conflictualismo principialista conduce, en efecto, «a un debilitamiento del paradigma constitucional, cuya normatividad jurídica, si bien respaldada por cartas constitucionales e internacionales, resulta devaluada a genérica normatividad ético-política, como si esas cartas, en lugar de normas supraordenadas a las ordinarias, fuesen, como escribe MAZZARESE, "meras declaraciones de intenciones políticas" ${ }^{71}$. De modo particular, concebir como conflictos lo que no son sino lesiones de los derechos primarios (inmunidades, libertades y derechos sociales) a manos de los derechos secundarios de autonomía política y negocial supone un indebido debilitamiento de los primeros por obra de unos derechos que en realidad son poderes; y «no podemos ignorar que las amenazas más graves a la demo-

66 Aplicar un principio, dice L. GIANFORMAgGIO, comporta siempre aplicar otro principio relevante en la situación específica, Studi sulla giustificazione giuridica, Torino: Giappichelli, 1986, p. 117.

${ }^{67}$ R. GuAstini, 1999: «Los principios en el Derecho positivo», trad. de J. FERRER, Distinguiendo. Estudios de teoría y metateoría del Derecho, Barcelona: Gedisa, p. 170.

${ }_{68}$ Me permito remitir aquí también a Justicia Constitucional y derechos fundamentales, cit., pp. 175 y ss.

69 Me refiero a la concepción de los derechos fundamentales como principios que defiende ALEXY, y que en lengua castellana ha sido objeto de un análisis exhaustivo y enriquecedor por parte de C. BERNAL PULIDO, 2003: El principio de proporcionalidad y los derechos fundamentales, Madrid: CEPC; y, con especial referencia a las leyes penales, por G. P. LOPERA MESA, 2006: Principio de proporcionalidad y ley penal, Madrid: CEPC.

${ }^{70}$ Así, en Garantismo. Una discusión sobre derecho y democracia, cit., p. 85. La negación de los conflictos «sería una extraña tesis ético-cognitivista», Principia Iuris, cit, $\$ 13.14$, vol. II, p. 72.

${ }^{71}$ Principia Iuris, cit., Introducción, nota 25, vol. I, p. 74. La referencia a T. MAZZARESE corresponde a «Diritti fondamentali e neocostituzioalismo: un inventario di problemi», cit., p. 15. 
cracia constitucional provienen hoy de dos potentes ideologías de legitimación del poder: la idea de la omnipotencia de la mayoría política y la idea de la libertad de mercado como nueva Grundnorm del actual orden globalizado» ${ }^{72}$. En resumen, presentar como conflictos dispuestos para la ponderación lo que son en realidad violaciones de derechos fundamentales equivale muchas veces a escamotear la fuerza normativa de tales derechos.

No dejan de llamar la atención estos temores de FERRAJOLI hacia las consecuencias de una concepción conflictualista de los derechos, pues representan un nuevo y sintomático distanciamiento respecto del neoconstitucionalismo. Para los conflictualistas, en efecto, una de las razones a favor de sus tesis es que propician mejor que cualesquiera otras el ejercicio de las libertades, asumiendo como criterio interpretativo el in $d u$ bio pro libertate y haciendo recaer sobre el poder una carga de justificación de toda posible interferencia. El conflictualismo, que es lo mismo que decir la teoría externa de los derechos fundamentales, daría primacía a la libertad negativa sobre la libertad positiva ${ }^{73}$ al tolerar o permitir innumerables cursos de acción con las mínimas restricciones, es decir, brindaría la más extensa protección de las esferas de libertad ${ }^{74}$. El juicio de ponderación, que es donde desemboca una visión conflictualista, ayuda a entender cualquier conducta prima facie como un ejercicio de libertad, cuya limitación definiti$v a$ ha de estar argumentada y contar con razones a favor al menos tan poderosas como para fundamentar una interferencia justificada en dicha conducta. En suma, la concepción de los derechos fundamentales que FERRAJOLI censura, lejos de suponer un debilitamiento de los derechos, alentaría su máxima extensión y sería por tanto la más acorde con la filosofía política liberal.

En mi opinión, es posible que ambas posiciones tengan su parte de razón. Si así puede decirse, FERRAJOLI apuesta a favor de la intensión y el conflictualismo a favor de la extensión; aquél teme que los juicios ponderativos conviertan en bagatela el núcleo mismo de los derechos, mientras que éste confía en que esa misma ponderación propicie una ampliación de las esferas protegidas. Si tenemos fe en la argumentación y en la aplicación judicial del Derecho, el conflictualismo puede alentar un incremento de los derechos y de sus ámbitos de protección, con la consiguiente minimización del poder; si somos menos optimistas ante la argumentación y la acción de los jueces, la concepción de FERRAJOLI nos garantiza tal vez menos derechos pero más fuertes. Recurriendo a ejemplos, para el conflictualismo no es difícil considerar como ejercicio de derechos fundamentales conductas tales como alimentar palomas (expresión del amor a los animales y por tanto del libre desarrollo de la personalidad), cubrirse con turbante u objetar frente a un deber jurídico que entendemos contrario a nuestra ideología o religión; pero es verdad que, a la inversa, corre el riesgo de mostrarse comprensivo ante la lesión de una inmunidad o de otra libertad si dicha lesión resulta proporcional para la satisfacción o realización de otro bien digno de tutela. Por el contrario, como veremos, FERRAJOLI no admitiría una ampliación del catálogo de derechos por vía interpretativa,

${ }^{72}$ Principia Iuris, cit., $\$ 13.14$, vol. II, p. 72.

73 En el sentido de I. BERLIN, 1969: Cuatro ensayos sobre la libertad, trad. de J. BAYÓn, Madrid: Alianza, 1988 , pp. 187 y ss.

74 Vid. M. BOROwsKI, «La restricción de los derechos fundamentales», cit., pp. 33 y ss.; G. P. LOPERA MESA, Principio de proporcionalidad y ley penal, cit., pp. 159 y ss. 
pero se mostraría mucho más estricto en la defensa de los derechos constitucionales, en particular de las inmunidades y derechos de libertad.

A los efectos que aquí interesan, en el esquema que nos propone FERRAJOLI cabe distinguir cinco esferas: a) las inmunidades (o libertades «frente a»), como la libertad de conciencia, la prohibición de la tortura o el derecho a la intimidad, cuyo rasgo característico es que su «ejercicio resulta imposible [...] no pudiendo interferir con ningún otro derecho»; $b$ ) los derechos-facultad o derechos de libertad activa (o «libertades de»), como la libertad de prensa o información, la libertad de reunión o la de asociación, que ciertamente suponen un ejercicio, pero carente «de efectos jurídicos en otras esferas de libertad»; c) los derechos autonomía, que son en realidad poderes cuyo ejercicio produce «efectos también en la esfera jurídica de otros», ya sea mediante las leyes, expresión indirecta de los derechos políticos, ya mediante los negocios jurídicos, expresión directa de los derechos civiles de autonomía privada; $d$ ) los derechos sociales que, a diferencia de todos los anteriores, representan expectativas positivas a prestaciones, como la educación o la asistencia sanitaria; y e) la esfera de la libertad natural o de la mera libertad, «aquella que sobrevive en el silentium legis (y que) no puede dejar de ser limitada por el derecho positivo», esto es, limitada por el ejercicio de los derechos autonomía ${ }^{75}$.

Comencemos por las inmunidades que, como sabemos, al no ejercerse difícilmente pueden entrar en conflicto con nadie, representando por el contrario límites insuperables frente a cualquier otro derecho o poder. Seguramente, un conflictualista consecuente rehusaría ver en las inmunidades límites tan absolutos que no admitiesen ponderación alguna, pero cuando menos establecería una distinción entre aquellas inmunidades que operan como reglas cerradas y concluyentes ${ }^{76}$ de aquellas otras que parecen hacerlo como principios. Por ejemplo, el honor y la intimidad o privacidad son inmunidades que para FERRAJOLI operan como limites a la libertad de expresión ${ }^{77}$, pero que según la doctrina y la práctica neoconstitucionalista están destinadas al conflicto; es más, tal vez este sea el supuesto paradigmático de conflicto y de ponderación entre derechos $^{78}$. En todo caso, conviene advertir que FERRAJOLI habla de inmunidades en una acepción muy estricta: inmunidades son sólo las libertades «frente a», aquellas «que

75 Principia Iuris, cit, $\$ 11.6$, vol. I, p. 758.

76 Así, el derecho del detenido a ser puesto a disposición judicial o en libertad en el plazo de setenta y dos horas (art. 17.2 CE) responde al modelo de las reglas: producida la condición de aplicación (que alguien esté detenido y hayan trascurrido setenta y dos horas) la autoridad gubernativa no tiene nada que ponderar; tan sólo ha de elegir entre la puesta en libertad o a disposición judicial. En otras palabras, existe un derecho fundamental absoluto a no estar detenido gubernativamente más de setenta y dos horas (dejando al margen, claro está, la legislación antiterrorista). Lo mismo ocurre, por ejemplo, con la abolición de la pena de muerte o con la proscripción de la tortura que, como dice el art. $15 \mathrm{CE}$, no podrá practicarse «en ningún caso».

77 Principia Iuris, cit, $\mathbb{S} 15,7$, vol. II, p. 338. En otro lugar (vid. infra nota 79), más que sostener la preferencia general o incondicionada de la inmunidad frente a la libertad activa, FERRAJOLI parece apostar por una integración normativa de ambos derechos, en la línea de la teoría interna de los derechos fundamentales a la que me referiré de inmediato.

${ }^{78}$ Valga el siguiente ejemplo de la STC 104/1986: «nos encontramos ante un conflicto de derechos ambos de rango fundamental, lo que significa que no necesariamente y en todo caso tal afectación del derecho al honor haya de prevalecer respecto del ejercicio que se haya hecho de aquellas libertades (las del art. 20), ni tampoco hayan de ser éstas consideradas como prevalentes, sino que se impone una necesaria y casuística ponderación entre uno y otras». Conviene subrayarlo: prima facie, la conducta enjuiciada representa un ejercicio de la libertad de expresión o información y, al mismo tiempo, supone una lesión del derecho al honor o a la intimidad. Quién triunfe en definitiva depende precisamente de cómo se resuelva el conflicto. 
no se ejercen», y hay derechos de contenido complejo que, junto a la dimensión de inmunidad, incluyen «facultades de» o libertades activas ${ }^{79}$. Pero, sea como fuere, su tesis es que las inmunidades no entran en conflicto con nadie, sino que pueden ser sólo violadas mediante el ejercicio de otros derechos, que es otra forma de decir que las inmunidades triunfan siempre. Algo que no parece compartido por la visión conflictualista propia del neoconstitucionalismo, al menos en relación con todos los derechos inmunidad; y los casos del honor y de la intimidad parecen ejemplos sobresalientes.

Por lo que se refiere al segundo supuesto, el de los derechos actividad (libertad de expresión, reunión, asociación) parece admitirse sin dificultades la existencia de conflictos. Aquí parece existir acuerdo con el neoconstitucionalismo, pero sospecho que FERRAJOLI mantiene una cierta imagen de tales conflictos cercana a la que suele llamarse «teoría interna» de los derechos fundamentales, según la cual entre los derechos y sus límites sería posible trazar una nítida frontera, de manera que podríamos catalogar ex ante las conductas tuteladas por el Derecho y aquellas otras incursas en el campo de actuación del límite ${ }^{80}$. En efecto, como ya se ha visto, resulta fácil imaginar conflictos entre la libertad de información y el derecho a la privacidad, o entre el derecho de huelga y el derecho a la salud «si aquél fuera ejercitable sin límites por parte del personal sanitario» ${ }^{81}$. Pero se trata de «conflictos» resueltos por lo común por la propia Constitución

79 Este es el origen de un malentendido que explica en parte un pequeño debate. En un trabajo anterior propuse como ejemplo de conflicto entre la libertad religiosa y el derecho a la salud el caso de una confesión que ordenase el sacrificio de animales con vulneración de la normativa sanitaria. Para FERRAJOLI la libertad religiosa no opera aquí en su faceta de inmunidad, sino de libertad activa («libertad de») y, de acuerdo con la clasificación de los derechos que acabamos de formular, tiene razón. Lo curioso es que, así entendida, tampoco reconoce conflicto alguno susceptible de ponderación; para él, sencillamente, la salud actúa como límite infranqueable a la libertad activa en la línea de la teoría interna, de la que nos ocuparemos seguidamente. Por lo que se refiere al segundo ejemplo, el caso real (STC 154/2002) es mucho más complejo y en mi trabajo apareció tal vez algo simplificado (lo que explica la respuesta) Se trata de unos padres, Testigos de Jehová, que fueron inicialmente condenados por la muerte de su hijo, al que no se le practicó una necesaria transfusión de sangre; transfusión a la que en realidad se oponía el hijo, titular del derecho de libertad religiosa, y no los padres, que a lo sumo observaron una conducta pasiva y a quienes sin embargo se les reprochó no autorizar lo que el menor rechazaba. El propio Tribunal Constitucional resolvió el caso en términos de conflicto entre la libertad religiosa y las obligaciones dimanantes del derecho a la vida del menor: «la aparición de conflictos en razón de las creencias religiosas no puede extrañar [...] La respuesta constitucional [...] sólo puede resultar de un juicio ponderado». Véanse L. PRIETO, «Constitucionalismo y garantismo», cit., p. 50; L. FerRAJOLI, Principia Iuris, cit, $\mathbb{S} 13$, nota 74, vol. II, p. 132.

${ }^{80}$ La teoría interna sostiene que las conductas o situaciones comprendidas bajo el amparo de un derecho fundamental resultan perfectamente claras desde los enunciados constitucionales, de manera que, mediando una correcta interpretación de los mismos, podemos delimitar con absoluta precisión la suerte de nuestro caso: o estamos en presencia de un ejercicio «típico» del derecho o libertad y entonces, por cierto, nada hay que ponderar ni discutir, porque nuestra posición es inexpugnable incluso para el legislador; o nos movemos por fuera del ámbito protegido por el Derecho, en cuyo caso tampoco hay nada que discutir porque el asunto queda librado a la decisión del legislador o de otras autoridades públicas. Esta teoría goza de bastante predicamento en la doctrina de lengua española. Por ejemplo, I. DE OTTO, 1988: «La regulación del ejercicio de los derechos y libertades», en L. Martín-Retortillo e I. DE OtTO, Derechos fundamentales y Constitución, Madrid: Civitas, pp. 107 y ss.; J. CiAnCIARDO, 2000: El conflictivismo en los derechos fundamentales, Pamplona: Universidad de Navarra, pp. 223 y ss.; P. SERNA y F. TOLLER, 2000: La interpretación de los derechos fundamentales. Una alternativa a los conflictos de derechos, Buenos Aires: La Ley, pp. 37 y ss.; T. DE DOMINGO, 2001: ¿Conflictos entre derechos fundamentales?, Madrid: CEPC, pp. 337 y ss. Cercano también a esta posición se encuentra J. A. GARCÍA AMADO, 2007: «Derechos y Pretextos. Elementos de crítica del neoconstitucionalismo», en M. CARBONELL (ed.), Teoría del neoconstitucionalismo, Madrid: Trotta, pp. 237 y ss.

${ }^{81}$ Principia Iuris, cit., $\$ 13.14$, vol. II, p. 73. Esto es, al existir límites, en este caso de origen legal merced a la remisión contenida en el art. 40 de la Constitución italiana, ya no cabe hablar de conflicto. El límite no es así un elemento a ponderar, sino un obstáculo insalvable al ejercicio del Derecho. 
que prevé límites expresos al ejercicio de las libertades o se remite a una configuración legal ${ }^{82}$; es decir, no se trata de verdaderos conflictos en sede interpretativa. «En todos estos casos, en definitiva, los derechos de libertad activa tienen exactamente los contenidos y, por tanto, los límites [...] establecidos por las normas que los enuncian» ${ }^{83}$.

Con todo, la adscripción de FERRAJOLI a la teoría interna, es decir, a la idea según a cual los derechos tendrían unos límites precisos ex ante, al menos cuando viniesen expresamente contemplados en la Constitución, resulta dudosa. Creo que lo demuestra este otro pasaje donde dice compartir mi opinión de que «los derechos están limitados, pero los límites también lo están y precisamente por los propios derechos, sin que desde la Constitución pueda deducirse en qué casos triunfan unos u otros» ${ }^{84}$. Esta opinión quiere expresar justamente la tesis de la teoría externa, haciéndose cargo de la inevitable imprecisión de los enunciados relativos a derechos, así como de la no menos inevitable vaguedad de las fronteras entre los derechos y sus límites. Por eso, como hemos dicho, para la teoría externa resulta perfectamente concebible que una misma conducta sea en principio ejercicio de un derecho y, al mismo tiempo y también en principio, que represente la vulneración de otro derecho. De ahí que proponga que toda conducta que presente una propiedad adscribible a un derecho fundamental (o, lo que me parece equivalente, que pueda considerarse dentro del marco semántico de un enunciado relativo a derechos, incluida, pues, la zona de penumbra) deba ser tratada como un caso de ejercicio del derecho fundamental en cuestión; y ese «debe ser tratada» significa simplemente que el asunto debe ser visto como un asunto con relevancia constitucional o, si se quiere, como un asunto en el que concurren razones a favor de su reconocimiento (aunque también concurran razones en contra). Esto explica la necesidad de distinguir un juicio prima facie y un juicio definitivo: prima facie podemos considerar que una determinada conducta es ejercicio de la libertad de información o del derecho de huelga, pero asimismo prima facie hemos de considerar que esa misma conducta lesiona el honor o el derecho a la salud, y por tanto valorar que existen razones a favor y en contra de la permisión. El juicio definitivo depende de la ponderación entre todas esas razones, que son razones constitucionales.

El capítulo en el que FERRAJOLI se muestra más rotundamente «anticonflictualista» es sin duda el de los derechos autonomía. Lo derechos de autonomía no colisionan con las libertades fundamentales, sino que vienen sometidos a su imperio; nuestra capacidad negocial privada y nuestra autonomía política indirectamente expresada en el ley tienen su frontera en el conjunto de los derechos fundamentales, y éste sería el meollo del constitucionalismo rígido: los derechos triunfan siempre sobre el mercado y sobre la política. Aquí existe una subordinación estructural de los derechos secundarios (de

82 Principia Iuris, cit., $\mathbb{\$} 13.14$, vol. II, p. 73.

${ }^{83}$ L. FERRAJOLI, Garantismo. Una discusión sobre derecho y democracia, cit., p. 87 (cursiva añadido). La adhesión a la teoría interna se muestra también clara en este fragmento: el derecho a la intimidad ha de ser considerado sobre la base de la interpretación de nuestro entero universo normativo, de manera que el mismo no ha de imponerse «donde prevalga el derecho de otros a la información. Pero esta precisión o integración [...] es normativa ex ante, y no ya operada arbitrariamente ex post: tiene su fundamento en normas del mismo grado o nivel de la del derecho a la intimidad, aunque no sepamos, a causa de las divergencias interpretativas que inevitablemente marcan la aplicación de la ley, en cuáles casos el derecho a la información (y a qué informaciones) será de hecho considerado prevalente sobre el derecho a la privacidad», «Entrevista a Luigi Ferrajoli», por A. GARCÍA FIgUeROA, Garantismo. Estudios sobre el pensamiento jurídico de Luigi Ferrajoli, cit, p. 528.

${ }^{84}$ Principia Iuris, cit., $\$ 13.14$, vol. II, p. 74 . Mi opinión en «Constitucionalismo y garantismo», cit., pp. 50 y ss. 
autonomía) a los derechos primarios (inmunidades, libertades y derechos sociales), y esto no ya en virtud de una cierta jerarquía de derechos ${ }^{85}$, «sino por la relación gradual que existe entre todos los derechos fundamentales constitucionalmente reconocidos, sean primarios a secundarios, y las normas o las situaciones singulares producidas por el ejercicio de los derechos secundarios [...] En el paso de los derechos de autonomía a las situaciones producidas por su ejercicio se desciende en efecto un grado o nivel normativo» ${ }^{86}$. Los derechos secundarios son poderes cuyo ejercicio mediante actos prescriptivos (contratos, leyes) produce efectos en la esfera jurídica de otros y por ello resulta siempre «vinculado, en cuanto a los efectos de grado subordinado que produce dicho ejercicio, a los derechos fundamentales pertenecientes al mismo grado o nivel normativo [...] De aquí la sujeción a la ley de todos los poderes, políticos y privados, que en la democracia constitucional son los unos expresión indirecta, a través de la representación política, y los otros expresión directa de los derechos de autonomía política y civil». Es decir, no es que los derechos autonomía se encuentren en un nivel jerárquico inferior; son «los efectos indirectos o directos de su ejercicio - las normas legales producidas por el ejercicio del poder legislativo, las situaciones producidas mediante el ejercicio de los poderes negociales- los que se encuentran en un grado subordinado al conjunto de los derechos fundamentales» ${ }^{87}$.

Creo que pocos rechazarían una idea tan atractiva que entronca la teoría de los derechos fundamentales con la venerable teoría de los derechos naturales y del contrato social: las instituciones nacen del consentimiento de los asociados y obtienen su legitimidad del servicio a los derechos; las leyes y demás disposiciones públicas sólo son legítimas si dan cumplimiento a la «razón social» que justifica la existencia misma de la asociación política, y esa «razón social» son precisamente los derechos fundamentales; la autonomía negocial, a su vez, sólo es legítima si se mueve en la esfera de libertad delimitada asimismo por los derechos. Y, sin embargo, me parece que es aquí donde se encuentra una de las discrepancias más relevantes entre FERRAJOLI y el neoconstitucionalismo. No es que éste rechace el sometimiento de las leyes y negocios al imperio de los derechos; es que antes de responder a la pregunta de si la ley o el contrato violan un derecho construye (y resuelve mediante ponderación) un conflicto intraconstitucional, es decir, un conflicto entre dos derechos fundamentales, de acuerdo con el modelo de ingeniería jurídica comentado al final del epígrafe anterior.

Examinemos por ejemplo el problema de la inalienabilidad de los derechos en las relaciones jurídico privadas. Ciertamente, la titularidad de los derechos no puede ser objeto de negociación en la medida en que la misma viene directamente atribuida por normas téticas ${ }^{88}$, pero creo que no cabe decir lo mismo de su ejercicio, que puede que-

${ }^{85}$ Aunque cabe esta interpretación. Véase P. COMANDUCCI, «Problemas de compatibilidad entre derechos fundamentales», en Garantismo. Estudios sobre el pensamiento jurídico de Luigi Ferrajoli, cit., pp. 112 y ss.

${ }^{86}$ Principia Iuris, cit., $\mathbb{\$} 12.14$, vol. I, p. 913.

${ }^{87}$ Ibidem, $\mathbb{S} 11.6$, vol. I, pp. 754-755.

${ }_{88}$ Que la titularidad sea inalienable tiene su fundamento en un rasgo en el que insiste mucho FERRAJOLI, y es que los derechos fundamentales (pero no sólo ellos) vienen reconocidos por normas téticas, mientras que otros muchos derechos (por excelencia, los patrimoniales) lo son por normas bipotéticas. Norma tética es aquella que atribuye inmediatamente situaciones o estatus a determinadas clases o sujetos, mientras que normas $h i$ potéticas son las que predisponen situaciones o estatus como efectos de los actos previstos como hipótesis. Vid. Principia Iuris, cit., $\$ \$ 8.3$ y 11.7 , vol. I, pp. 424 y ss.; pp. 759 y ss. 
dar condicionado, y mucho, por lo que se pacta en un contrato, en el que incluso pueden concurrir eventualmente derechos fundamentales de dos partes; por ejemplo, si aceptamos, como hay que aceptar en España, que la llamada libertad de enseñanza incluye el derecho de los sujetos privados a fundar colegios con «ideario», entonces irremediablemente resulta afectada la libertad ideológica de los profesores, que han de «vender» parte de ella para impartir clase. Hasta dónde pueda llegar esa «venta» es algo que también queda librado al juicio de ponderación, pero, en todo caso, si esto es así, me parece artificioso decir que los derechos representan un límite insuperable para la autonomía privada. De hecho, la amplia discusión que existe acerca de la virtualidad de los derechos en las relaciones jurídico privadas se explica porque esos derechos entran en conflicto con las cláusulas pactadas o, en general, con los derechos de la otra parte.

La respuesta de FERRAJOLI a una objeción semejante formulada por Moreso ${ }^{89}$ es la siguiente: en el «conflicto» entre la libertad del trabajador para vestirse como quiera y la directiva del empresario para que use uniforme, o en el de la cláusula testamentaria que impone al heredero la condición de no contraer matrimonio, no hay en realidad conflicto alguno, pues tanto el trabajador como el heredero son absolutamente libres para contratar o aceptar la herencia. En cambio, le parece obvio que se produciría una lesión del derecho a la imagen y a la dignidad de la persona si el empresario exigiese a las cajeras de un supermercado atender en top-less, o una lesión de la libertad de contraer matrimonio si el mismo empleador condicionase la estabilidad contractual al mantenimiento de la soltería ${ }^{90}$. Es posible que la solución que alcanzásemos desde la teoría externa y por vía ponderativa fuera similar. Lo que cambia es el modo de argumentar, aunque creo que también en algún caso la propia conclusión. Como los partidarios de la teoría interna, FERRAJOLI sugiere que los derechos presentan un contenido definitivo ex ante, fijado en la Constitución y tal vez en la ley, de modo que cualquier interferencia pública o privada será o no legítima según penetre o no en la esfera tutelada, es decir, en el contenido «verdadero» del Derecho. La teoría externa y el juicio de ponderación se desarrollan en dos fases: en una primera se constata la relevancia de una conducta desde la óptica de dos principios o derechos enfrentados: condicionar la forma de vestir o el estado civil forma parte prima facie de la autonomía negocial y, por tanto de un derecho, pero al propio tiempo interfiere en el ámbito de otros derechos (la libertad de indumentaria, la dignidad, la libertad matrimonial). A su vez, en una segunda fase guiada ya por la ponderación, habrá de valorarse la proporcionalidad entre el grado de lesión de un derecho y de satisfacción de otro.

Argumentando desde la teoría externa, por ejemplo, podría considerarse aceptable la exigencia de uniforme y no, en cambio, la de top-less, pero ello no porque en el primer caso el trabajador sea libre de aceptar, pues ese argumento vale también para el segundo, sino porque estimamos que este último comporta un sacrificio de la dignidad y de la libertad que resulta desproporcionado y carente de justificación. Ahora bien, ¿qué clase de condicionamientos en la indumentaria pueden considerase legítimos y cuáles no? Esta es una pregunta que no admite una respuesta concluyente en abstracto: dependerá del tipo de trabajo, de la clase de exigencia empresarial, etc. Algo parecido

\footnotetext{
${ }^{89}$ Véase J. J. MORESO, «Sobre los conflictos entre derechos», en Garantismo. Estudios sobre el pensamiento jurídico de Luigi Ferrajoli, cit, pp. 164 y ss.

${ }^{90}$ L. Ferrajoli, Principia Iuris, cit., $\$ 13$, nota 82, pp. 133-134.
} 
cabe decir del segundo ejemplo: puede ser que existan mejores razones a favor de la cláusula testamentaria que condiciona el disfrute de la herencia al hecho de no contraer matrimonio que a favor de esa misma cláusula incorporada a una relación laboral; pero de nuevo el motivo tampoco puede ser que el heredero sea libre de aceptar la herencia, pues también lo es el trabajador para rescindir su contrato. En suma, no hay un indubitado contenido «verdadero» del derecho ex ante, sino un contenido ex post, que se obtiene después y no antes de ponderar, es decir, de tomar en consideración las razones que hablan a favor de uno u otro derecho ${ }^{91}$.

Nuestra cuarta categoría de derechos son los derechos sociales. En opinión de FERRAJOLI, lo que suele presentarse como un conflicto entre los derechos sociales y otros derechos fundamentales generalmente no es tal cosa, sino un problema de costes económicos, de elecciones políticas sobre la distribución de los recursos. Aquí FERRAJOLI tiene toda la razón: no se deben confundir las dificultades fácticas con las jurídicas, lo que tampoco significa que éstas nunca puedan producirse, y el propio autor reconoce algún caso de efectiva colisión ${ }^{92}$. Ahora bien, detrás de las decisiones políticas no hay sólo dificultades fácticas o de falta de medios, sino que hay también opciones en favor de un derecho u otro, pues los derechos sociales pueden entrar en colisión entre sí o con otros derechos ${ }^{93}$. Mantener este debate sólo en la esfera política ${ }^{94}$ supone renunciar a una posible, aunque mínima, tutela judicial de las posiciones subjetivas de prestación. Presentar la cuestión como un conflicto entre derechos o bienes constitucionales supone abrir la puerta a una ponderación capaz de colmar, siquiera parcialmente, las lagunas dejadas por la ley y los reglamentos; pues cabe decir que los derechos sociales constitucionales son tan importantes que no pueden quedar por completo a disposición de lo que decidan las mayorías o de lo que acuerden los particulares en ejercicio de su libertad negocial ${ }^{95}$. Justamente en eso consisten, para el propio FERRAJOLI, los derechos fundamentales, en quedar a salvo de la política y del mercado.

Finalmente, queda la cuestión de la mera libertad o de la libertad natural, aquella que surge del silentium legis. La teoría externa que suele acompañar al neoconstitucionalismo no tiene inconveniente en construir un derecho general de libertad ${ }^{96}$, derecho sin duda prima facie pero que tiene la virtud de brindar la más amplia protección de la libertad, haciendo recaer sobre el poder la carga de la argumentación o justificación de las eventuales restricciones; la cláusula genérica del «libre desarrollo de la personalidad» (art. 2.1 de la Ley Fundamental alemana, art. 10.1 de la Constitución española), la liber-

${ }_{91}$ Una exposición clara de las diferencias entre teoría interna y teoría externa de los derechos fundamentales puede verse en el trabajo de C. BERNAL PULIDO, «Refutación y defensa del neoconstitucionalismo», en Teoría del neoconstitucionalismo, cit., pp. 308 y ss.

${ }_{92}$ Así, en la prohibición o restricción de un género de producción nociva se produce una colisión entre el derecho a la salud y el derecho al trabajo, Los fundamentos de los derechos fundamentales, cit., p. 352.

93 Véase R. AlEXY, 1986: Teoría de los derechos fundamentales, trad. de E. GARZÓN VALDÉs, Madrid: CEPC, 1993, pp. 492 y ss.

${ }_{94}$ Como en algún momento parece sugerir L. FerRAJOLI: «es claro que, siendo indiscutible la obligación de dictar una legislación de desarrollo que permita satisfacer sus "contenidos esenciales", esas opciones corresponden al legislador ordinario y a la administración pública», Principia Iuris, cit., $\$ 13.14$, vol. II, p. 73.

${ }_{95}$ Sobre la tutela judicial de los derechos sociales he tratado en 1998: «Los derechos sociales y el principio de igualdad sustancial», en Ley, principios, derechos, Madrid: Dykinson,, pp. 96 y ss.

96 Véanse R. Alexy, Teoría de los derechos fundamentales, cit., pp. 331 y ss.; C. BERNAL Pulido, El principio de proporcionalidad y los derechos fundamentales, cit., pp. 646 y ss.; G. P. LOPERA MESA, Principio de proporcionalidad y ley penal, cit., pp. 281 y ss. 
tad ideológica y religiosa o simplemente la libertad personal suelen invocarse como cobertura constitucional de un tal derecho que nos permitiría afirmar que en el marco de un constitucionalismo de los derechos toda acción u omisión está permitida, a menos que esté prohibida u ordenada por una norma formal y materialmente constitucional ${ }^{97}$.

Pues bien, una vez más FERRAJOLI parece distanciarse del neoconstitucionalismo: «la mera libertad, aquella que sobrevive en el silentium legis, no puede dejar de ser limitada por el Derecho positivo» ${ }^{98}$, es decir, representa el ámbito de actuación natural donde pueden desarrollarse con toda libertad los derechos-poder de autonomía, tanto en la dimensión pública o de las leyes como en la privada o negocial. En virtud del principio de constitucionalidad, las únicas facultades intangibles son aquellas que aparecen consagradas como libertades o derechos fundamentales y «es evidente» que la mera libertad «no tiene nada que ver con los derechos fundamentales de libertad» ${ }^{99}$.

Sin embargo, tampoco esto resulta muy claro. En un trabajo anterior FERRAJOLI decía que los derechos de autonomía que interfieren en la libertad natural son «poderes limitados en cuanto tales por el Derecho» ${ }^{100}$. Pero, salvo que se refiriese a los límites formales (competencia y procedimiento) para el ejercicio de los derechos de autonomía, ¿en qué límites sustantivos cabe pensar si resulta que nos hallamos ante una esfera de «no derecho»? En Principia Iuris podemos encontrar un principio de respuesta: «ciertamente esta libertad (la mera libertad) es una libertad protegida — y no es pocofrente a las violaciones ilegítimas: frente a los actos ilícitos, como por ejemplo las violencias configuradas como delitos por las leyes penales, y frente a los actos inválidos, como por ejemplo las disposiciones arbitrarias y contrarias a las leyes» ${ }^{101}$; es decir, la libertad natural está subordinada al legítimo ejercicio de cualquier poder y por ello puede ser reducida o suprimida por cualquier acto preceptivo legítimo.

Pero, si esto es así, parece que también la libertad natural — sin dejar de ser el campo para el ejercicio de los derechos autonomía - goza de una protección iusfundamental. De un lado, si está protegida frente a los actos ilícitos (por ejemplo, el delito de coacciones) entonces es que representa un bien jurídico merecedor de tutela penal y para FERRAJOLI sólo los bienes fundamentales, y en particular los derechos fundamentales, se hacen acreedores a dicha tutela ${ }^{102}$. Luego no parece aventurado afirmar que, frente a los actos ilícitos, la posición de la libertad natural no difiere mucho de la posición de los derechos fundamentales: quien mediante la violencia me impide u obliga a asistir a misa está lesionando mi libertad religiosa y comete un delito de coacciones; y quien del mismo modo me impide llevar sombrero o tener animales domésticos está lesionando mi libertad natural o no regulada, pero comete un similar delito de coacciones. De otro lado, fuera ya de los actos ilícitos, resulta que la mera libertad puede ser limitada por los actos prescriptitos (leyes, contratos) siempre que sean «legítimos» o que no consti-

${ }^{97}$ He defendido la posibilidad de construir este derecho general de libertad o «norma de clausura» del sistema de libertades en varias ocasiones. En particular en Justicia constitucional y derechos fundamentales, cit., pp. 249.

${ }_{98}$ Principia Iuris, cit., $\mathbb{\$} 11.6$, vol. I, p. 758.

${ }_{99}$ Ibidem, $\mathbb{\$} 1.6$, vol. I, p. 133.

${ }^{100}$ L. FERRAJOLI, Los fundamentos de los derechos fundamentales, cit., p. 311.

${ }_{101}$ Principia Iuris, cit., $\$ 1.6$, vol. I, p. 133.

102 No procede aquí extenderse en la teoría de FERRAJOLI sobre el bien jurídico. Véase Derecho y Razón, cit., $\$ 33$, pp. 464 y ss. 
tuyan «disposiciones arbitrarias». Parece, por tanto, que la interferencia sólo está permitida cuando se acredita la legitimidad o no arbitrariedad de la medida. Pero ¿esto no equivale a imponer sobre el ejercicio de los derechos de autonomía una carga de justificación, que es precisamente lo que pide la tesis del derecho general de libertad? En otras palabras, me parece que esa prevención frente a la arbitrariedad puede ser equivalente a la exigencia de justificación que, desde la teoría externa, se requiere para toda interferencia en la esfera de la libertad natural.

En definitiva, las esferas de lo indecidible y de lo indecidible que no que vienen delimitadas por los derechos fundamentales presentan unos perfiles mucho menos nítidos desde el momento en que se reconoce que los propios derechos entran en conflicto y que tales conflictos no admiten una respuesta concluyente en el plano abstracto de la validez, sino que remiten su configuración completa y definitiva a un juicio de ponderación efectuado, en cada caso, a la vista de los derechos en pugna. Y, si esto es así, como piensa el neoconstitucionalismo, entonces resulta que la garantía jurisdiccional y la argumentación no pueden ser sólo una mera actividad de constatación o verificación, sino también en parte constructiva. En otras palabras, es verdad que las esferas de lo indecidible y de lo indecidible que no aparecen delimitadas por los derechos fundamentales, pero no enteramente ex ante o desde la Constitución, sino expost o tras la resolución de los eventuales conflictos. De ahí que el protagonismo judicial sea un rasgo típico del neoconstitucionalismo.

\section{ALGUNAS CONCLUSIONES}

Principia Iuris constituye la gigantesca construcción teórica del garantismo y representa una de las más estimulantes versiones del constitucionalismo. La filosofía política que late tras la pulcritud formal de su método axiomático recupera y lleva hasta sus últimas consecuencias lo mejor y más ambicioso del programa ilustrado y contractualista que quiso ver en el Estado y en las instituciones unos artificios instrumentales al servicio de lo único reconocido como natural, los derechos de las personas de carne y hueso. Con Principia Iuris se perfila, en efecto, uno de los modelos más exigente, minucioso y amplio de unos derechos fundamentales que son la verdadera «razón social» del constitucionalismo democrático y que encarnan otros tantos requerimientos para que el poder y su fuerza, irremediablemente malos y carentes de cualquier legitimación inmanente, presenten un rostro más tolerable o menos tenebroso. Sin embargo, y tal vez como consecuencia de su fidelidad a la Ilustración, hay dos aspectos en los que FERRAJOLI se aleja claramente de las formulaciones neoconstitucionalistas más divulgadas. El primero tiene que ver con a tesis básica del llamado positivismo conceptual: no hay en FERRAJOLI la más mínima concesión ni al neoiusnaturalismo constitucionalista, ni al positivismo incluyente o incorporacionismo (no, al menos, a varias de sus consecuencias), ni, en fin, a ninguna solución de compromiso que pueda sonar a constitucionalismo ético. Por numerosos que sean los contenidos sustantivos (morales) que incorporen las Constituciones como criterios de validez de las normas, por decisivas que sean las consecuencias que ello tiene para nuestra comprensión del Derecho - y creo que nadie como FERRAJOLI ha puesto más empeño en examinar y extraer conclusiones de este fenómeno- la separación entre el Derecho y la moral, siempre externa y crítica frente al poder, queda firmemente asegurada. 
El segundo aspecto tiene que ve con la teoría de la argumentación. El garantismo y en general el constitucionalismo suelen ser acusados en Europa de judicialistas, en el sentido de propiciar un control judicial de todos los actos de poder, incluida la Ley, tomando como parámetro los escuetos preceptos constitucionales, no siempre precisos y concluyentes. El déficit de racionalidad y con ello de legitimidad que esto pueda suponer es compensado por buena parte de los enfoques constitucionalistas mediante una compleja y poderosa teoría de la argumentación jurídica ${ }^{103}$, en la que acaso depositen más confianza de la debida. Pero no es este el caso de FERRAJOLI: el extraordinario poder de censura que el garantismo deposita sobre los jueces quiere hacerse soportable a través de una visión cognitivista de la interpretación donde el juez está llamado a constatar y, en muy escasa medida, a escoger, valorar o decidir. Las cláusulas materiales de la Constitución y en especial los derechos no le invitan al juez garantista a ponderar pesos y proporcionalidades relativas, ni a realizar juicios consecuencialistas; lo invitan simplemente a subsumir. La ley y los pactos privados limitan nuestra libertad natural, y aquí nada hay que discutir; a su vez, la ley y los pactos vienen sometidos a la barrera infranqueble y «evidente» de los derechos constitucionalizados, y al parecer tampoco hay aquí nada que discutir; y en fin, los derechos se formulan como mónadas aisladas cuyos contornos aparecen perfectamente delimitados desde su enunciado constitucional, y basta con aplicarlos a los distintos supuestos de hecho.

GUASTINI ha llamado la atención sobre el cognitivismo de la concepción garantista de la interpretación y sobre su propósito por reducir al mínimo la discrecionalidad judicial: «tácitamente, hace suya la tesis ilustrada (de Montesquieu y Beccaria) según la cual el poder jurisdiccional sólo puede funcionar como garantía o barrera frente al poder ejecutivo a condición de ser un poder en cierto modo nulo [...] (el juez) no debe tener espacios de valoración u opción [...] debe ser sólo un poder cognitivo (cognitivismo) y no un poder decisional (decisionismo) ${ }^{104}$. No cabe duda que un juez empeñado en colmar lagunas y en resolver (o esquivar) antinomias o imbuido de una visión conflictualista de la Constitución y de sus derechos, un juez abierto al género de argumentación y a los cálculos de proporcionalidad que están implicados por el juicio de ponderación, resulta difícilmente compatible con esa visión cognitivista.

Por supuesto, FERRAJOLI no comparte la imagen más ingenua del juez como «boca muda» de la ley o de la Constitución, una imagen nacida en la Ilustración pero divulgada y asumida como dogma por el paleopositivismo. Él es consciente no sólo de la discrecionalidad o subjetividad que acompaña a todo juicio interpretativo ${ }^{105}$, sino también del poder de disposición que entraña la denuncia de lagunas y antinomias, es decir, que entrañan los juicios de validez ${ }^{106}$. Sin embargo, esa imagen de «boca muda» creo que

${ }^{103}$ Con razón M. ATIENZA ve en el constitucionalismo uno de los factores que explican el desarrollo de la argumentación en las últimas décadas, 2006: El Derecho como argumentación, Barcelona: Ariel, p. 18.

104 R. GUASTINI, 1993: «I fondamenti teorici e filosofici del garantismo», en L. GIANFORMAGGIO (ed.), Le ragioni del garantismo, Torino: Giappichelli, p. 53.

105 La interpretación «comporta siempre, a causa de los márgenes de indeterminación e imprecisión del lenguaje legal, espacios de discrecionalidad interpretativa destinados a ser llenados por opciones y juicios de valor que le confieren una inevitable dimensión prescriptiva», Principia Iuris, cit., Introducción, 5, vol. I, p. 21.

106 Ya en Derecho y razón, cit., p. 877, se puede leer que el Estado constitucional «debe admitir paradójicamente un poder de disposición del juez, si no en la calificación de los hechos como delitos, sí en la calificación como inválidas de las leyes que permiten la calificación dispositiva de los hechos como delitos». Con razón M. GASCón califica ésta como una «consecuencia aporética» del planteamiento ferrajoliano: el juez que 
viene a representar una especie de ideal regulativo. Las funciones públicas, dice FERRAJOLI, pueden dividirse en dos grandes categorías, reconducibles a las dos grandes dimensiones de la producción jurídica: «voluntad y conocimiento, innovación y conservación, disposición y verificación» ${ }^{107}$; si el primer elemento de cada una de esas parejas caracteriza a las funciones de gobierno, el segundo es el rasgo característico de las funciones de garantía jurisdiccional. De ahí que sus fuentes de legitimación resulten opuestas: auctoritas non veritas facit legem para las funciones políticas o de gobierno; veritas non auctoritas facit legem para las jurisdiccionales.

Queda por plantear una última cuestión que aquí ya no podrá ser desarrollada. Hemos mostrado que el neoconstitucionalismo, o al menos una de sus versiones más influyentes, conjuga el rechazo a dos tesis o enfoques del positivismo situados aparentemente en niveles distintos: el primero relativo a la separación conceptual entre Derecho y moral, y el segundo a propósito de la interpretación y de las posibilidades del razonamiento jurídico. Y hemos mostrado también cómo FERRAJOLI se distancia con más o menos énfasis de esa versión del neoconstitucionalismo. Ahora bien, ¿es posible mantener un riguroso positivismo conceptual, en la línea de FERRAJOLI y, al propio tiempo, aceptar como saludable una teoría de la interpretación y de la función judicial que estimula la aplicación directa de la Constitución (por encima de lagunas y antinomias), los juicios ponderativos y la visión conflictualista que hemos comentado, en la línea del neoconstitucionalismo? ¿Resulta viable defender el punto de vista externo y simultáneamente apelar a una argumentación racional a partir de contenidos sustantivos como forma de mitigar la indeterminación del Derecho, pero también como forma directa de realización del programa constitucional? Creo que buena parte del neoconstitucionalismo respondería negativamente ${ }^{108}$, sosteniendo algo así como que la incorporación de valores morales en la cúspide del sistema jurídico y el reconocimiento de la fuerza normativa de la Constitución conducen sin remedio a la conexión necesaria entre Derecho y moral, a la primacía del punto de vista interno y al desplazamiento del centro de gravedad en el Derecho de la norma al razonamiento, de la nomodinámica a la nomoestática; como si existiera una inevitable implicación recíproca entre unas cosas y otras. Opino que no es así, que resulta factible (y deseable) mantener la venerable tesis positivista de la separación y, al mismo tiempo, defender el acierto y la fecundidad de la teoría y de la práctica argumentativa emprendidas desde el neocontitucionalismo.

pone de relieve las lagunas y las antinomias «goza de facultades potestativas o valorativas que van contra la lógica de la estricta legalidad en cuanto principio que excluye que el juez tenga, aparte de un poder de denotación y connotación, también un poder de decisión», «La teoría general del garantismo», en Garantismo. Estudios sobre el pensamiento jurídico de Luigi Ferrajoli, cit., p. 29.

107 Principia Iuris, cit., $\$ 12.7$, vol. I, p. 876.

108 En este sentido la inteligente observación de A. GARCÍA FigUEROA, «Ser o no ser normativo: un dilema para el positivismo jurídico», en E. Dimulis y E. O. Ramos Duarte (eds.), Positivismo jurídico, Sao Paolo: Método (en prensa). 
